\title{
Comparative spigot ontogeny across the Spider Tree of Life
}

\author{
Rachael E Alfaro ${ }^{\text {Corresp.. }}{ }^{1}$, Charles E Griswold ${ }^{2}$, Kelly B Miller ${ }^{1}$ \\ 1 Museum of Southwestern Biology, Division of Arthropods, University of New Mexico, Albuquerque, New Mexico, United States \\ 2 Entomology, California Academy of Sciences, San Francisco, California, United States \\ Corresponding Author: Rachael E Alfaro \\ Email address: mallis@unm.edu
}

Spiders are well known for their silk and its varying use across taxa. Very few studies have examined the silk spigot ontogeny of the entire spinning field of a spider. Historically the spider phylogeny was based on morphological data and behavioral data associated with silk. Recent phylogenomics studies have shifted major paradigms in our understanding of silk use evolution, reordering phylogenetic relationships that were once thought to be monophyletic. Considering this, we explored spigot ontogeny in 22 species, including Dolomedes tenebrosus and Hogna carolinensis, reported here for the first time. This is the first study of its kind and the first to incorporate the Araneae Tree of Life. After rigorous testing for phylogenetic signal and model fit, we performed 60 phylogenetic generalized least squares analyses on adult female and second instar spigot morphology. Six analyses had significant correlation coefficients, suggesting that instar, strategy, and spigot variety are good predictors of spigot number in spiders, after correcting for bias of shared evolutionary history. We performed ancestral character estimation of singular, fiber producing spigots on the posterior lateral spinneret whose potential homology has long been debated. We found that the ancestral root of our phylogram of 22 species, with the addition of five additional cribellate and ecribellate lineages, was more likely to have either none or a modified spigot rather than a pseudoflagelliform gland spigot or a flagelliform spigot. This spigot ontogeny approach is novel and we can build on our efforts from this study by growing the dataset to include deeper taxon sampling and working towards the capability to incorporate full ontogeny in the analysis. 
1 Comparative spigot ontogeny across the Spider Tree of Life

2 Rachael E. Alfaro ${ }^{1}$, Charles E. Griswold ${ }^{2}$, Kelly B. Miller ${ }^{3}$

$3 \quad{ }^{1}$ Museum of Southwestern Biology, Division of Arthropods, University of New Mexico,

4 Albuquerque, New Mexico, USA

$5{ }^{2}$ Entomology, Curator Emeritus, California Academy of Sciences, San Francisco, California, 6 USA

$7{ }^{3}$ Museum of Southwestern Biology, Division of Arthropods, University of New Mexico,

8 Albuquerque, New Mexico, USA

9 Corresponding Author:

10 Rachael Alfaro (Mallis) ${ }^{1}$

11 Division of Arthropods, Museum of Southwestern Biology, 1 University of New Mexico,

12 MSC03-2020, Albuquerque, NM 87131, USA

13 Email address: mallis@unm.edu; rachael.mallis@gmail.com 
14 Abstract: Spiders are well known for their silk and its varying use across taxa. Very few studies

15 have examined the silk spigot ontogeny of the entire spinning field of a spider. Historically the

16 spider phylogeny was based on morphological data and behavioral data associated with silk.

17 Recent phylogenomics studies have shifted major paradigms in our understanding of silk use

18 evolution, reordering phylogenetic relationships that were once thought to be monophyletic.

19 Considering this, we explored spigot ontogeny in 22 species, including Dolomedes tenebrosus

20 and Hogna carolinensis, reported here for the first time. This is the first study of its kind and the

21 first to incorporate the Araneae Tree of Life. After rigorous testing for phylogenetic signal and

22 model fit, we performed 60 phylogenetic generalized least squares analyses on adult female and

23 second instar spigot morphology. Six analyses had significant correlation coefficients, suggesting

24 that instar, strategy, and spigot variety are good predictors of spigot number in spiders, after

25 correcting for bias of shared evolutionary history. We performed ancestral character estimation

26 of singular, fiber producing spigots on the posterior lateral spinneret whose potential homology

27 has long been debated. We found that the ancestral root of our phylogram of 22 species, with the

28 addition of five additional cribellate and ecribellate lineages, was more likely to have either none

29 or a modified spigot rather than a pseudoflagelliform gland spigot or a flagelliform spigot. This

30 spigot ontogeny approach is novel and we can build on our efforts from this study by growing the

31 dataset to include deeper taxon sampling and working towards the capability to incorporate full

32 ontogeny in the analysis. 
34 Silk is the trait most commonly associated with spiders. Silk is produced by glands that service

35 spigots on specialized appendages called the spinnerets. Spinnerets are a distinguishable synapomorphy of Araneae (Coddington, 1989; Platnick, 1990; Platnick et al., 1991; Griswold et al., 2005; Wheeler et al., 2016). The morphology of the spinnerets and the silk spigots they possess provides an advantage enabling spiders to create simple to complex silk structures from sheet-webs to tangle webs (Selden et al., 2008). The evolutionary history of spiders has long been explored in the context of silk evolution. With the arrival of molecular phylogenetics and phylogenomics studies, our understanding of spider systematics has changed drastically from the formerly well accepted hypotheses based on morphological and behavioral traits (Platnick, 1977;

43 Griswold et al., 2005; Bond et al., 2014; Fernández et al., 2014; Garrison et al., 2016; Wheeler et al., 2016).

These recent updates have led to a paradigm shift in our perception of silk use evolution.

The most dramatic changes have occurred in the "Orbiculariae" where data mainly from orb web weaving behavior provided weak corroborating evidence of monophyly, whereas contradictory data were lacking. Specifically, the orb web was considered a key adaptation in spider evolution (Bond \& Opell, 1998). However, despite previous support for this hypothesis through morphological and behavioral data (Coddington, 1986; Coddington, 1990; Hormiga \& Griswold, 2014), the monophyly of Orbiculariae (cribellate Deinopoidea + viscous Araneoidea) has now been rejected based on thorough molecular and phylogenomics studies (Dimitrov et al., 2012; Bond et al., 2014; Fernández et al., 2014; Garrison et al., 2016; Wheeler et al., 2016). The former

54 "Orbiculariae" members Deinopoidea (cribellate orb builders) are now closer to the RTA clade

55 (includes wolf spiders and jumping spiders) rather than to the Araneoidea (sticky-silk orb weavers) and Deinopoidea may not even be monophyletic (Garrison et al., 2016; Wheeler et al., 57 2016). 
Some studies of silk evolution have used web ontogeny as a tool to reconstruct ancestral

59 web conditions or plesiomorphic traits in silk use. Studies many from to the Araneoidea

60 (Robinson \& Lubin, 1979; Eberhard, 1985; Eberhard, 1986; Barrantes \& Madrigal-Brenes, 2008;

61 Barrantes \& Eberhard, 2010), suggested that early instar webs and behavior resembled possible

62 ancestral states. In studies of both Tengella perfuga F. Dahl (1901) and Tengella radiata (W.

63 Kulczyński, 1909), early instar webs resembled simple sheet webs rather than the complex funnel

64 structures lined with cribellate silk observed in adults (Barrantes \& Madrigal-Brenes, 2008;

65 Mallis \& Miller, 2017). This may be the ancestral condition for this lineage. However, Mallis \&

66 Miller (2017) observed T. perfuga lay down cribellate silk in an orb-like spiral within the

67 horizontal sheet. This observation makes sense, considering recent phylogenomics revisions and results of the new Araneae Tree of Life (AToL) (Wheeler et al., 2016) project, where the sister group to the RTA clade is now hypothesized to be the cribellate orb weavers of the Uloboridae (Bond et al., 2014; Fernández et al., 2014; Garrison et al., 2016; Wheeler et al., 2016). between fecundity and silk use that is driving spider evolution and where more recently derived clades have lost silk as a foraging tool (Blackledge et al., 2009). Energy metabolism in a spider species is related to natural history traits such as foraging activity level and courtship behaviors (Anderson, 1970; Prestwich, 1977; Anderson \& Prestwich, 1982; Prestwich, 1983; Anderson, 1996). Foraging activity level is also tied to the type of silk used and web building or non-web building. Cribellate silk has been historically viewed as a plesiomorphic trait in spiders, which requires the development and use of the cribellum (a plate derived from the ancestral anterior median spinnerets) and the calamistrum (a setal comb on leg IV to pull the silk fibers out) (Hawthorn \& Opell, 2002; Blackledge et al., 2009; Pechmann et al., 2010). It is possible that that 
82 compared to cribellate silk users supports the hypothesis of "adaptive escape" from metabolically

83 costly cribellate silk production and represents increased resource allocation to reproduction in

84 spiders that produce viscous silk or that are non-web building altogether (Blackledge et al., 85 2009).

We wanted to explore the potential correlations of foraging strategy and silk use and did

87 so in the context of the silk spigots themselves. Each spigot is serviced by a specific gland and

88 each type of silk serves a different purpose. This has been most well explored in Araneidae

89 (Coddington, 1989; Yu \& Coddington, 1990; Townley \& Tillinghast, 2009; Garb, 2013). There

90 must be a caveat that in most cases the actual gland has not been observed and the spigot type is

91 assigned a gland type name based on inferential evidence such as position, fine structure and

92 ontogeny. Most of the Araneomorphae spiders possess five types of spigots (Griswold et al.

93 2005). These are the 1) major ampullate gland spigots (MAP) on the anterior lateral spinneret

94 (ALS), which produces dragline silk and structural silk for orb webs; 2) piriform gland spigots

95 (PI) on the ALS that produce silk that is used to attach the dragline to a substrate surface; 3)

96 minor ampullate gland spigots (mAP) on the posterior median spinneret (PMS), whose silk is

97 used as a temporary scaffolding for the spiral in the orb web and whose purpose in non-web

98 builders is not yet defined; 4) aciniform gland spigots (AC) on the PMS and 5) aciniform gland

99 spigots on the PLS, which produce silk used in prey wrapping and lining egg sacs, as well as the

100 sheet portions in non-orb webs. Another two types appear in the adult female instar of the

101 Entelegynae, i.e., spiders with sclerotized, flow-through female genitalia (Griswold \& Ramírez,

102 2017) and their closest relatives (Austrochiloidea, Palpimanoidea and Leptonetidae), which

103 together form "CY spigot clade" (Wheeler et al., 2016). These are 6) cylindrical (=tubuliform)

104 gland spigots (CY) on the PMS and 7) cylindrical gland spigots on the PLS which are female

105 specific and produce fibers that form the egg sac (Fig.1, and see Fig. 1 in Garb, 2013). Because 
106 they appear on two different and morphologically distinct spinnerets, we treat the AC and CY

107 gland spigots on the PMS and PLS separately. Araneoids also possess flagelliform (FL) gland

108 and aggregate (AG) gland spigots, which produce the sticky capture spiral in orb webs (Yu \&

109 Coddington, 1990; Townley \& Tillinghast, 2009; Garb, 2013). The former Deinopoids do not

110 possess flagelliform or aggregate gland spigots but instead possess a cribellum, paracribellar

111 spigots on the PMS (which attach the cribellate silk to its axial line), and the pseudoflagelliform

112 (PF) gland spigot (a possible MS spigot homologue) that produces the axial lines of cribellate

113 fibers (Hajer, 1991; Eberhard \& Pereira, 1993). These cribellar fibrils serve as a prey-capture

114 mechanism, rather than the viscous capture spiral of orb webs. Other, more recently derived

115 cribellate spiders, such as the zoropsid T. perfuga, possess a modified spigot on the PLS which is

116 thought to produce the axial line (R.E. Alfaro, unpublished data). Zoropsids do not possess

117 paracribellar spigots on the PMS. However, in T. perfuga, the modified spigot is flanked by two

118 smaller, unknown spigots whose function is currently undetermined (R.E. Alfaro, unpublished

119 data; also observed in T. radiata in Griswold et al., 2005). We will refer to these flanking spigots

120 of the modified spigot as 'flankers'.

121 Adult spider silk spigot morphology has been used as a morphological character system in 122 many phylogenetic studies (Coddington, 1989; Platnick, 1990; Platnick et al., 1991; Griswold et 123 al., 2005; Ramírez, 2014). However, few studies have explored or incorporated the ontogeny of

124 the whole spinning field (Wąsowska, 1977; Yu \& Coddington, 1990; Hajer, 1991; Townley \&

125 Tillinghast, 2009; Dolejš et al., 2014; R. Carlson \& C.E. Griswold, unpublished data). By

126 incorporating the ontogeny of the spinning field, we can observe when activity patterns shift in

127 one adult sex, as well as the appearance or disappearance of spigots, or whether certain spigots

128 increase in number with each molt to a new instar (Townley \& Tillinghast, 2009; Mallis \& Miller, 129 2017; R.E. Alfaro, unpublished data). 
tenebrosus N.M. Hentz (1884), a fishing spider (Pisauridae), and Hogna carolinensis (C.A.

132 Walckenaer, 1805), a wolf spider (Lycosidae). We also use the recently published AToL (Wheeler

et al., 2016) to conduct the first statistical phylogenetic comparative study of spigots and silk use

in spiders. We pooled these two datasets (Dolomedes and Hogna), as well as our previous study

of the cribellate zoropsid Tengella perfuga, along with five previously published studies and one unpublished dataset (Wąsowska, 1977; Yu \& Coddington, 1990; Hajer, 1991; Townley \& unpublished data). comparative methods focusing on correlations between predictor variables such as foraging strategy, and response variables such as the average number of aciniform spigots on the PMS. Therefore, considering the spigot ontogeny of several species across the phylogeny with various foraging strategies and types of silk expressed, and the new Araneae Tree of Life (Wheeler et al., 2016), we may be able to disentangle the variables that are correlated such as spigot number, type, foraging strategy and determine what may be driving silk use evolution after correcting for shared evolutionary history (phylogenetic correction). The four questions guiding our approach are: 1) Is there a relationship between foraging strategy (web vs. non-web) or specific foraging strategies (i.e. ambush, active, sit \& wait, etc.) and the number of certain silk spigots in spiders?

\section{Materials \& Methods:}


153 Spider husbandry:

154 Rearing conditions and lab colony maintenance for Hogna carolinensis and Dolomedes

155 tenebrosus follow Mallis \& Miller (2017). The founding female H. carolinensis was collected in

156 Bernalillo County, New Mexico (D. Lightfoot, 10-Sept-2014) carrying second instar spiderlings

157 on her abdomen. A gravid D. tenebrosus with an egg sac was sent to us from Bedford County,

158 Virginia (K. Benson, 29-June-2014). When possible, two to three replicates of each instar were

159 randomly sacrificed for scanning electron microscopy (SEM) imaging to account for variation

160 among individuals of the same instar. After developing through the first few instars of both

161 species, colony survival strongly declined. Subsequently, single samples were collected at each

162 instar for D. tenebrosus, while after the seventh instar in H. carolinensis, a single female was

163 followed to adulthood (twelfth instar). The founding females, as well as instar vouchers, were

164 deposited at the Museum of Southwestern Biology, Division of Arthropods (MSBA 50049 -

165 50070).

166 SEM preparation, imaging and spigot mapping:

167 We dissected in 100\% EtOH, and then critical point dried using a Denton DCP-1 critical point

168 dryer, and mounted specimens of each instar for D. tenebrosus and H. carolinensis onto standard

169 SEM stubs using a combination of copper tape and non-conductive glue at California Academy

170 of Sciences (CAS). Finally, all SEM stubs were coated in gold/palladium using a Cressington

171 Sputter coater $108(6002,6006$ series $)$ that used Argon gas to facilitate coating. At CAS, we

172 obtained SEM images on the Hitachi SU-3500 scanning electron microscope. Up to 20 views of

173 each instar spinning field for both species were captured, covering all spinnerets for two

174 replicates of each instar. These SEMs were used to create spigot maps which were translated into

175 a spigot ontogeny dataset for each species (methods outlined in Coddington (1989) and Griswold

176 et al., (2005); see Table 1). Spigot mapping allows for notation of type, functionality and 
177 placement of silk spigots on each spinneret, as well as tracking the growth of the spinning fields

178 from instar to instar and the appearance of interesting spigot formations.

\section{Spigot ontogeny datasets:}

180 We compiled a large spigot ontogeny dataset of 22 species comprising thirteen spider families

181 using previously published studies and unpublished datasets (Table 2; Wąsowska, 1977; Yu \&

182 Coddington, 1990; Hajer, 1991; Townley \& Tillinghast, 2009; Dolejš et al., 2014; R. Carlson \&

183 C.E. Griswold, unpublished data). Three of those sources came from our lab colonies not only

184 for D. tenebrosus and H. carolinensis, as reported here but also the cribellate zoropsid, Tengella

185 perfuga (R.E. Alfaro, unpublished data). The dataset included the appearance, type, and number

186 of specific spigots on each spinneret (Fig. 1, Table S1). While some studies reported tartipores

187 (remnant structures of spigots from previous instar spigots) and others the presence of nubbins

188 (non-functioning spigots), all studies reported the number of the seven common (shared) spigot

189 types across all the species of this study: 1. MAP gland spigots, 2. PI gland spigots, 3. mAP

190 gland spigots, 4. AC gland spigots on the PMS, 5. CY gland spigots on the PMS, 6. AC gland

191 spigots on the PLS and 7. CY gland spigots on the PLS. We standardized the final data set to

192 include these 'standard 7' spigots (Table S1).

\section{Variables of Interest:}

194 From the standardized datasets, we selected five independent or predictor variables for

195 phylogenetic comparative analyses, and chose twelve dependent or response variables for the

196 final analyses. The independent variables were (Table 2):

197 1. Strategy: Foraging strategy scored as 0: web builder or 1: non-web builder.

198 2. Specific: Specific foraging strategies, scored as 1: sit \& wait, 1.5: ambush, 2: sit \& pursue, 2.5: stalking, 3: active, 4: sheet web, 4.5: funnel web or 5: orb web. Sit \& pursue, while similar to sit $\&$ wait, is defined as an intermediate state between sit $\&$ wait and 
201

202

203

204

205

206

207

208

209

210

211

212

213

214

215

active hunting (Schmitz \& Suttle, 2001, Miller et al., 2013). With a sit \& wait strategy, the otherwise motionless spider grabs the prey when it comes within striking distance, whereas with sit \& pursue, the otherwise motionless spider runs after the prey when it comes within several centimeters proximity and pursues the prey until captured (Schmitz \& Suttle, 2001, Miller et al., 2013).

3. Silk: Main type of silk used, scored as 1: none/MAP dragline, 1.5: burrow, 2: aciniform sheet, 3: cribellate, or 4: viscous silk, i.e., that produced from the aggregate gland spigots.

4. Type: A measure of the variety of spigots the species possessed beyond what we called the standard 7. These scored as 1: standard 7, 1.5: standard $7+$ modified piriform gland spigots on the ALS, 2: standard $7+$ modified spigot on PLS, 2.5: standard $7+$ modified spigot on PLS with two 'flankers' + cribellum, 3: standard 7 + aggregate and flagelliform gland spigots on the PLS or 4: standard $7+$ cribellum, paracribellar gland spigots on the PMS and a pseudoflagelliform gland spigot on the PLS.

5. Instar: Maximum number of instars that a species goes through to reach adulthood (females).

The twelve dependent variables were continuous and were the average number of spigots for each of the 'standard 7' found in all the spider species spinning fields. We focused on the adult female instar as well as the second instar, i.e., when all spiders emerge from the egg sac.

Specifically, for adult females, the seven dependent variables were average number of spigots for: 1. MAP gland spigots on the ALS, 2. PI gland spigots on the ALS, 3. mAP gland spigots on the PMS, 4. AC gland spigots on the PMS, 5. CY gland spigots on the PMS, 6. AC gland spigots on the PLS and 7. CY gland spigots on the PLS. For second instars, the five dependent variables were the average number of spigots for: 8. MAP gland spigots on the ALS, 9. PI gland spigots on the ALS, 10. mAP gland spigots on the PMS, 11. AC gland spigots on the PMS and 12. AC gland spigots on the PLS. Cylindrical gland spigots are only found in adult female spiders, which is why they are not included with the second instars. 
Phylogenetic comparative analyses have typically dealt with at least two continuous

228

variables. Methods have improved to accommodate the increase in Type 1 Error associated with discrete variables such that analyses like phylogenetic generalized least square models (PGLS) can be robustly performed (Graber, 2013; Maddison \& FitzJohn, 2015). While theoretically repeated-measures or a factorial ANOVA are possible in a phylogenetic context, the methods of incorporating them into phylogenetic comparative analyses are not yet developed (Guo et al., 2007). Thus, our time series study could not be analyzed as a whole unit. To gain a picture of the potential effects of ontogeny, we performed several PGLS analyses on the adult female spigot numbers as well as those of the second instars. These include the stage at which all spiders emerge from the egg sac and are the most similar in condition (second instars) to the stage when the most diversification and growth in spigots appears (adult female stage).

\section{Phylogeny:}

We used the topology of the recently published Araneae Tree of Life (AToL) (Wheeler et al., 2016) for the 22 species included in our study. At the time of publication of this manuscript, the AToL sequences have not been publicly released. Thus, while we were not able to generate a time-calibrated tree or one with branch lengths equal to a rate of molecular evolution, we could use the published topology and create two phylograms. One phylogram had all branch lengths equal to 1 and the other was an ultrametric tree with the same topology (Fig. 2), using the ape (version 4.1) package in $R$ (Paradis et al., 2004). Both trees were used in model testing for phylogenetic comparative analyses and ultimately, we used the ultrametric topology in our final analyses.

\section{Phylogenetic comparative analyses:}


249 All analyses were performed in $R$ using RStudio (version 3.2, R Core Team, 2016; RStudio,

250 2017). First, we tested both sets of dependent and independent variables for phylogenetic signal

251 using the phytools (version 0.5-64) package in $R$ (Revell, 2012). All independent variables had

252 strong phylogenetic signal with Blomberg's K (Blomberg et al., 2003) and Pagel's $\lambda$ (Pagel, 1999)

253 being close to 1 and with significant p-values while most of the dependent variables did not show

254 phylogenetic signal (Table 3). Despite this, given the strong signal in the predictor variables, we

255 decided to proceed with PGLS analyses. Because the K values were so close to 1, a Brownian

256 motion model of evolution was the best fit. We further tested various models of evolutionary

257 rate, and confirmed the Brownian model of evolution being the best fit (Results S1). Next, using

258 both trees, we tested PGLS models using generalized least squares method of model selection

259 with single term up to all five independent variables included. We used the $R$ packages, $n l m e$ and

260 MuMIn (version 1.15.6) to test model fit (Bartón, 2016; Pinheiro et al., 2017). PGLS analyses

261 required the use of the ape, geiger (version 2.0.6), nlme (version 3.1-131) and phytools packages

262 in $R$ (Paradis et al., 2004; Harmon et al., 2008; Revell, 2012; Pinheiro et al., 2017). With delta

263 AICc values equal to zero or very close to zero between terms, and a significant p-value

264 associated with the single term Instar, we determined that single term models were the best fit

265 with the trees and the datasets for PGLS as there was no significant effect of adding additional

266 terms (Table 4, Results S2). We ran a total of 35 PGLS analyses covering each of the adult

267 female dependent variables (average numbers of specific silk spigots) and 25 PGLS analyses

268 covering each of the second instar dependent variables using the ape and geiger packages in $R$

269 (Paradis et al., 2004; Harmon et al., 2008). We did this with both trees, and while the specific

270 analyses results differed, the main conclusions did not. We also performed ANOVA analyses on

271 the independent variable means derived through the PGLS models. Because all the independent

272 variables were discrete the ANOVA analyses served to corroborate the PGLS results. Here we

273 report the significant PGLS coefficient of correlation results (Table 5) using a maximum 
274 likelihood approach, with a Brownian model of evolution and the ultrametric tree. The 60 full

275 PGLS analyses and ANOVA results using the ultrametric tree are available in Results S3, S4.

\section{Ancestral character estimation:}

277 Finally, we used the ultrametric tree and the ace function in the ape package in $R$ (Paradis et al., 278 2004) to conduct ancestral character estimation on the diverse, singular spigots found on the PLS 279 to explore the unresolved question of whether these spigots are homologous structures or not. 280 The spigots of interest were the modified spigot (MS) found in some cribellate and ecribellate 281 spiders, the pseudoflagelliform gland spigot (PF) found in cribellate orb weavers and the 282 flagelliform gland spigot (FL) found in viscous orb weavers. We added five additional taxa, 283 using data derived from adult female SEM images in Griswold et al. (2005) to allow for broader 284 taxon sampling deeper into the phylogeny. These species were the cribellate Hypochilus pococki N.I. Platnick (1987; Hypochilidae), Kukulcania hibernalis (N.M. Hentz, 1842; Filistatidae), Thaida peculiaris F. Karsch (1880; Austrochilidae), Megadictyna thilenii F. Dahl (1906; Megadictynidae) and ecribellate Nicodamus mainae M.S. Harvey (1995; Nicodamidae). The

288 Nicodamoidea (Megadictynidae plus Nicodamidae) are sister to all Araneoidea, while the other 289 families are sister to the Araneoidea + RTA clades (Wheeler et al., 2016). We used a maximum

290 likelihood method with a model of the weighted rate matrix of substitutions for these spigots

291 (Table 6). As we describe below, we constrained our rate matrix (Table 6) that we used to model 292 substitution rates across branch lengths based on prior knowledge about historical possession of 293 the flagelliform gland, pseudoflagelliform gland and modified spigots in each taxon (Table 6) 294 (Platnick et al., 1991; Griswold et al., 2005; Dimitrov et al., 2016; Wheeler et al., 2016). Some of

295 the more recently derived clades within the Araneoids (Dimitrov et al., 2016) have lost 296 flagelliform gland spigots (i.e. Mimetidae, Arkyidae). We ranked the transition to Loss (of 297 spigots) as 1 substitution and that to none, pseudoflagelliform, or modified spigots (not observed 
298 anywhere in this lineage) as 0 substitutions, or no likelihood (Table 6). Because they are found in

299 cribellate groups ancestral to both the RTA and Araneoid clades, we ranked all transitions for 300 modified spigots to the other four states as 1 substitution (Table 6). One interpretation of Dollo's

301 Law is that it is easier to lose a structure than to re-evolve it (Dollo, 1893) and this influenced 302 how we weighted the remaining matrix for Pseudoflagelliform, Loss, and the possible None (no 303 spigot) cases. Since one of the cribellate ancestral species, Kukulcania hibernalis, does not 304 possess anything corresponding to a modified or pseudoflagelliform gland spigot, and is 305 classified as 'None', we conservatively allowed for a single substitution from None to Flagelliform, Modified and Pseudoflagelliform in our rate matrix (Table 6). Finally, since the cribellate orb weaving sister group to the RTA clade possesses a pseudoflagelliform gland spigot (PF) and RTA clade members possess modified (MS) or no spigots, we allowed for 0 substitutions in this direction. We also allowed for a substitution rate of 1 between Pseudoflagelliform and Flagelliform as we do not know whether the ancestral orb weaver possessed pseudoflagelliform or modified spigots (Bond et al., 2014; Garrison et al., 2016; 312 Wheeler et al., 2016). We then plotted the likelihoods of states at each node on the ultrametric 313 phylogeny (Fig 3, Results S5).

315 independent variables from the PGLS analyses on the ultrametric tree with increased taxa:

316 Strategy, Specific, Silk and Type (Results S5). The constrained rate matrices for each variable 317 along with explanations for the given matrices are provided in Table S2. We did not include 318 maximum instar, as those data were not available in the literature for the five additional taxa. 319 Also, due to its variability within a species (see Table S1), ancestral character estimation may not 320 be a useful tool to use to understand maximum instar in silk evolution. 


\section{Results:}

322

323

\section{Spigot ontogeny of Dolomedes tenebrosus and Hogna carolinensis:}

All instars of D. tenebrosus (instars 2-13) and more than half of the instars (instars 2-7 and 12) of H. carolinensis were observed and sampled from lab colonies for SEM imaging to assess the spigot ontogeny of the full spinning field of these lycosoid spiders (Homann, 1971; Griswold, 1993; Polotow et al., 2015). Dolomedes tenebrosus reached adulthood in thirteen instars while H. carolinensis reached adulthood in twelve (Table 1).

Anterior lateral spinnerets: Both species possessed two MAP gland spigots, except for the adult male stage (Table 1, Fig. 4). Piriform gland spigots increased in number to adulthood (Fig. 4). However, in adult male D. tenebrosus, PI gland spigots decreased from the penultimate instar, which led to sexual dimorphism (Table 1). It was not until later instars of $D$. tenebrosus and $H$. carolinensis that the number of PI gland spigots increased in greater magnitude from instar to instar (Figs. 4A-E, Table 1). We also observed sensilla (sensory pores) in the MAP fields of both species (Fig. 5).

Posterior median spinnerets: Both species possessed two mAP gland spigots, except for the adult male stage of D. tenebrosus (Table 1, Fig. 6). CY gland spigots did not appear until the adult female and probably penultimate female instars. Penultimate $D$. tenebrosus possessed at least one pre-cylindrical gland spigot (Fig. 6F). D. tenebrosus adult females bore many more CY gland spigots than H. carolinensis (Fig. 6C). In D. tenebrosus, AC gland spigot numbers did not change at $4 \mathrm{AC}$ gland spigots for instars $2 / 3$, then at $5 \mathrm{AC}$ gland spigots through instars 4/5/6, and then $8 \mathrm{AC}$ gland spigots for instars 8/9/10 (Table 1, Figs. 6D, E). Both males and females lost AC gland spigots in the final molt to adulthood. In H. carolinensis, AC gland spigots dropped in number at instar 4 and remained at $3 \mathrm{AC}$ gland spigots for the next two instars (Table 1, Figs. 6A, 
344 B). By the adult instar, the number was far greater in the female $H$. carolinensis than the female 345 D. tenebrosus (Table 1, Fig. 6C).

346 Posterior lateral spinnerets: Cylindrical gland spigots also appeared in the penultimate female 347 stage with the three pre-spigots visible (Fig. 7F). Adult female H. carolinensis possessed a single 348 CY gland spigot compared to the $28 \mathrm{CY}$ gland spigots in adult female D. tenebrosus (Table 1). 349 Aciniform gland spigots presented different trends between the two species (Table 1, Figs. 7, 8). In D. tenebrosus, AC gland spigot numbers slowly increased with the same number persisting for 2-3 instars, then increasing (Fig. 7). We also observed loss of spigots in the final molts to adulthood in both males and females (Table 1). In H. carolinensis, a sharp decrease to $3 \mathrm{AC}$ gland spigots occurred in instar 4 and persisted through instar 5, then increased to 7 AC gland spigots in instar 6 persisting through instar 7 (Table 1, Fig. 8). The female H. carolinensis possessed more AC gland spigots than the female D. tenebrosus. In both species, a larger spigot was tentatively identified as a 'modified spigot' (see Griswold et al., 2005: 61; character 96), with a potential pre-modified spigot observed in the penultimate female stage of $D$. tenebrosus. These made no other appearance in the ontogeny the spinning fields of either species (Table 1, Figs. 7, 359 8).

\section{Phylogenetic comparative analyses:}

361 We compiled a full spigot ontogeny dataset of 22 species representing thirteen spider families and 362 scored the five independent, predictor variables: Strategy, Specific, Silk, Type, Instar (Table S1, 363 Table 2). After determining that the independent variables had strong phylogenetic signal, 364 whereas only three of the twelve dependent response variables did, we decided to proceed with 365 the phylogenetic generalized least squares analyses (Table 3). After thorough tree and model 366 selection analyses, we determined that single term models were the best fit along with the 
367 ultrametric tree and a Brownian model of evolution (Table 4, Fig. 2). We ran a total of 60 PGLS

368 analyses (Results S3, S4) and here report the significant results of those analyses (Table 5).

369 In the adult female analyses, we found that Instar was a significant predictor in a few

370 cases. For piriform gland spigots (ALS), the coefficient of correlation between Instar and

371 average number of spigots was significant (Table 5). This was also the case for aciniform gland

372 spigots of the PMS (Table 5). For female PI gland spigots, Type, or the variety of spigots

373 possessed, was also a significant predictor of Average number of PI (Table 5). Of interest, the

374 female mAP gland (PMS) spigots did show strong phylogenetic signal and Strategy was a

375 significant predictor of Average number of mAP gland spigots. This means that, after the bias of

376 the correlation due to phylogeny was accounted for through the PGLS, the species classification

377 of either being a web builder or not had a strong coefficient of correlation with the average

378 number of mAP gland spigots possessed (Table 5).

379 In the second instar analyses, we found that Instar was also a significant predictor or 380 independent variable. For MAP gland (ALS) spigots in second instars, the coefficient of 381 correlation between Instar and Average number of MAP gland spigots was significant (Table 5).

382 Spiders possessed one, two or no MAP gland spigots at the emergence from the egg sac (second

383 instar) (Table S1). For the mAP gland (PMS) spigots, which did show strong phylogenetic signal

384 in preliminary testing, Instar was a significant predictor of the Average number of mAP gland

385 spigots (Table 5). Second instar spiders possessed two, one or no mAP gland spigots at this first

386 stage outside of the egg sac (Table S1).

387 Ancestral character estimation of singular spigots on the PLS:

388 We performed a maximum likelihood ancestral character estimation (ACE) of potentially

389 homologous spigots producing axial lines, i.e., the singular spigot on the PLS. We used the 
390 ultrametric tree and overall scoring of whether a species possesses a spigot and if so, which

391 spigot it is: Flagelliform, Modified, None (never historically possessing a singular spigot),

392 Pseudoflagelliform, or Loss (previously possessing a singular spigot) of a spigot. We used a

393 constrained rate matrix for the five states as our model of substitution rates for the ACE analyses

394 (Table 6). The log likelihood value for the analysis was -46.023 . Within this analysis we

395 calculated the scaled likelihoods of states at the root (Flagelliform gland spigot: 0.000, Modified

396 spigot: 0.365 , None (no singular spigot that produces axial lines): 0.635 , Pseudoflagelliform

397 gland spigot: 0.000, Loss: 0.000), as well as the other nodes of the phylogram produced (Fig. 3,

398 Results S5). In our color-coded results, the predominately red clade was the Araneoidea, which

399 includes viscous orb weavers (FL spigot) and the pirate spiders (Mimetidae) which do not possess

400 a FL spigot as adults (Loss) (Fig. 3). However, as very young juveniles mimetids possessed

401 vestigial FL and aggregate gland spigots on the PLS (Table S1, Townley \& Tillinghast, 2009).

402 The predominately green clade (MS spigot) was the RTA clade, with loss of MS spigot (black) in

403 many of the tip species, while just sister to that were the yellow clades (Pseudoflagelliform),

404 which included the cribellate sheet (Phyxelida) and cribellate orb weavers (Hyptiotes).

405 Additional plesiomorphic cribellate taxa, possessing MS spigots (green, Thaida, Hypochilus) or

406 no unique spigot on the PLS (blue, Kukulkania) were included for deeper phylogenetic sampling

407 (Fig. 3). Finally, the results suggested that, at the ancestral root node, the PLS singular spigot

408 was more likely to have been a modified spigot than a pseudoflagelliform gland spigot, and that

409 the ancestor either possessed a modified spigot or no singular spigot (Fig. 3, Table 4).

410 We followed a similar procedure for maximum likelihood ancestral character state

411 estimation for four of the five independent variables: Strategy, Specific, Silk and Type. The

412 constrained rate matrices used as the model for the analyses are given in Table S2. The resulting

413 state likelihood values for each node are also given in Results S5 with the previous ACE node 
414 results. For the variable Strategy (foraging strategy), the ancestral character estimation model has 415 a log likelihood of -14.73. At the root, the ancestral state was "Web" or web building (likelihood $416=1.0)$ rather than no web or loss of web (Fig 9, Results S5). Therefore, the ancestral state for the 417 araneoids and lycosoids was a web builder. Specific (specific foraging strategy) ACE model has 418 a log likelihood of -58.65. At the ancestral node, the states are for web building (Fig 10). The 419 ancestor of lycosoids and araneoids likely spun a funnel web (likelihood $=0.812$ ) or a sheet web 420 (likelihood $=0.084)$; an orb web (likelihood $=0.105)$ is less likely (Fig 10, Results S5). The 421 ACE model for Silk (main type of silk expressed) has a log likelihood of -44.61 . The ancestor of 422 araneoids and lycosoids produced cribellate silk (likelihood = 1.0; Fig 11, Results S5). Finally, 423 the ACE model for Type (variety of silk spigot types) had a log likelihood of -36.14 . The 424 ancestral state at the root node was undetermined, but the two states with the highest likelihoods 425 were cribellate spiders possessing either Standard 7 + Cribellum + Paracribellar spigots 426 (likelihood $=0.398$ ) or Standard $7+$ Cribellum + Pseudoflagelliform + Paracribellar spigots 427 (likelihood $=0.433)$. All additional five states had much lower likelihoods (Fig 12, Results S5).

Discussion:

This is the first published full ontogeny of the spinning apparatus of both $D$. tenebrosus and $H$. carolinensis. This is also the first statistical phylogenetic comparative analysis exploring questions in silk use and evolution across several spider taxa. By creating a standardized dataset across 22 species, we could unite the few existing spigot ontogeny studies into a comparative and phylogenetic context (Wąsowska, 1977; Yu \& Coddington, 1990; Hajer, 1991; Townley \&

434 Tillinghast, 2009; Dolejš et al., 2014; R. Carlson \& C.E. Griswold, unpublished data; R.E. Alfaro, 435 unpublished data). 
436 Spigot ontogeny of $\boldsymbol{D}$. tenebrosus and $\boldsymbol{H}$. carolinensis:

437 Both D. tenebrosus and H. carolinensis are large-bodied lycosoids. Dolomedes tenebrosus

438 belongs to the Pisauridae family, the fishing or nursery web spiders, and employs a sit \& wait

439 foraging strategy (Table 2) whereas $H$. carolinensis, belonging to the diverse Lycosidae family, 440 employs a sit \& pursue strategy (Table 2) (Schmitz \& Suttle, 2001, Miller et al., 2013). While

441 both have a similar number of instars to adulthood, the two species differ dramatically from each 442 other in the loss and regain of aciniform gland spigots on the PMS and PLS (Table 1, Figs. 6, 7, 443 8). In D. tenebrosus, AC gland spigot numbers on the PMS do not change for multiple instars 444 slowly increasing after two to three instars with a dramatic increase in the final molts. In $H$. 445 carolinensis, AC gland spigot numbers drop and remain low for two to three instars before 446 gradually increasing, until a similar dramatic increase in number with the final molt (Table 1, Fig. 447 6). The same interesting trend was also observed for aciniform gland spigots on the PLS in both 448 species (Table 1, Figs. 7, 8). These trends were not observed in other lycosoids previously 449 studied including other members of the Lycosidae (Wąsowska, 1977; Dolejš et al., 2014). H. 450 carolinensis do not form webs. D. tenebrosus instars were observed in the lab to build silk 451 scaffolding where they rested and at times fed (R.E. Alfaro, unpublished data). It is possible that 452 this difference in silk use and foraging strategy between H. carolinensis and D. tenebrosus, 453 especially the lack of regular web building, could account for the trends we observed with AC 454 gland spigot numbers. Both species were observed on a few occasions to wrap prey items after a 455 preliminary bite before returning to bite again. This is an ancient behavior seen in many other 456 taxa including the Araneoidea, Phyxelididae, and other members of the RTA clade. It is also 457 possible that they have evolved alternative uses for aciniform silk or do not need to produce this 458 silk until the adult instars when numbers of spigots on both spinnerets increase. 
460 this has also been recorded in other lycosoids and araneid spiders (Wąsowska, 1977; Townley \&

461 Tillinghast, 2009; Dolejš et al., 2014). We were not able to rear our H. carolinensis males to

462 adulthood in the lab colony, but given the trends in other Lycosidae, we would expect to observe

463 sexual dimorphism as well (Dolejš et al., 2014). In most spiders, regardless of lineage or

464 cribellate or ecribellate status, adult males lose (abort) spigots of all types in the final molt: this is

465 likely due to the shift in life history strategy of abandoning webs or territories to actively forage

466 and look for females (Wąsowska, 1977; Yu \& Coddington, 1990; Hajer, 1991; Townley \&

467 Tillinghast, 2009; Dolejš et al., 2014; R. Carlson \& C.E. Griswold, unpublished data; R.E. Alfaro, 468 unpublished data).

Adult females of both species possessed a potential modified spigot (MS) on the PLS. A modified spigot was not reported for other lycosoids in previous studies (Wąsowska, 1977;

Dolejš et al., 2014). Modified spigots have been reported as singular or, in some cases of

472 cribellate silk users among members of the RTA clade, which includes lycosoids, the MS may 473 occur with flanking spigots (Griswold et al., 2005; R.E. Alfaro, unpublished data). It is possible

474 that this modified spigot in lycosoids could be homologous to the pseudoflagelliform gland spigot 475 (PF) observed in cribellate lineages sister to the RTA clade, e.g., Phyxelida tanganensis (E.

476 Simon \& L. Fage, 1922) and Hyptiotes paradoxus (C.L. Koch, 1834) (Table S1; Peters, 1984;

477 Peters, 1995; Griswold et al., 2005; Eberhard, 2010; Eberhard \& Barrantes, 2015; R. Carlson \&

478 C.E. Griswold, unpublished data). In contrast, it should be noted that in species with modified

479 spigots, adult males typically possess an MS nubbin, which we did not observe in male $D$.

480 tenebrosus (Ramírez, 2014, Table 5). To confirm these observations in D. tenebrosus and $H$.

481 carolinensis, replicate adult female and male specimens are necessary.

\section{Phylogenetic comparative analyses:}


483 Six analyses had significant correlation coefficients after correcting for the bias of shared

484 evolutionary history, suggesting that Instar, Strategy, and Type (spigot variety) are good

485 predictors of spigot number in spiders (Table 5). Although most of the PGLS analyses found no

486 significant correlation of the five independent variables with the 12 dependent variables of spigot

487 numbers, this is not altogether surprising considering the PGLS analyses remove the bias of

488 correlation due to shared evolutionary history. It is possible that with broader taxon sampling

489 deeper in the phylogeny, trends may emerge beyond those explained by phylogenetic signal. As

490 our analyses currently cannot include as a variable the full ontogeny dataset per species, it is also

491 more likely with future developments of more complex statistical analyses within a phylogenetic

492 context that will allow us to include the full ontogeny picture of each species, we will be able to

493 gain a better understanding of what is driving silk spigot evolution in spiders.

Maximum number of instars (Instar) served as a proxy for body size or body condition in

each spider species. Within a species with variation in maximum instar, we observed higher

numbers of spigots in the individuals of older instars (Table S1). Finding a significant correlation

between Instar and Average number of spigots in adult female aciniform and piriform gland spigots is not unexpected, considering these spigots increase in number with each instar (Table

S1, Table 5). The more nutrition a juvenile spider consumes in one instar influences how much growth occurs in the molt to the next instar. Spiders with a steady food supply may invest in an increased number of instars to ensure better body condition at the adult stage, which could lead to a trend of increase in spigot numbers (R.E. Alfaro, unpublished data). Piriform gland spigot numbers were also positively correlated with Type (variety of spigots possessed) (Table 5). Piriform gland silk is used as a cement for other silk fibers, particularly the major ampullate gland fibers in dragline silk (Garb, 2013). In orb weavers, piriform gland silk is used to cement 
507 dragline to the substrate to prevent the spider from falling (Garb, 2013). Orb weavers and

508 lycosoids possess different types of silk spigots and have different uses for the shared spigots

509 they possess (Table S1, Table 2); for example, MAP gland silk may be used to construct aerial

510 frames (orb weavers) vs. surface dragline (lycosoids); aciniform gland silk may be used as web

511 material in wolf spiders who spin funnel webs (the genus Hipassa) rather than as a prey wrapping

512 material (orb weavers) (Mathew et al., 2011; Garb, 2013). It is possible that these differences in

513 use are due to the types of spigots they possess and their differing foraging strategies (web

514 building vs. predominately active hunting) and are what is causing this positive correlation we

515 observed (Table 5). Finally, in adult female PGLS analyses, Strategy (web vs. non-web) was a

516 significant predictor of the number of mAP gland spigots on the PMS. The coefficient of

517 correlation was small, but when we look at the full ontogeny data (Table S1), we see a clear

518 differentiation between araneoids and the others. In the adult female stage, araneoids lose one

519 mAP gland spigot and retain one functional spigot, whereas in the other groups, from the

520 lycosoids to the cribellate web builders, all female spiders retain the two mAP gland spigots that

521 they possessed throughout their ontogeny (Table S1). The clear correlation between strategy as a

522 predictor and mAP number as a response is expected since all araneoids possess one mAP spigot

523 and the remaining spider groups possess two (Correlation coefficient: $0.291, t=2.448, p=0.024$ :

524 Table 5). This may have withstood the phylogenetic correction of the PGLS, because several of

525 the non-araneoids within our study also spin webs.

The PGLS analyses for second instars were largely non-significant. The lack of

527 significant correlation between predictor and response variables may be due to second instars

528 being more similar. Many spiders start out with the same general number of spigots upon

529 emergence from the egg sac (second instar) and differentiation between foraging strategies may

530 not be apparent at this instar, e.g., some second instar web builders do not spin webs (Table S1, 
531 Hajer et al., 1991; Barrantes \& Madrigal-Brenes, 2008; R.E. Alfaro, unpublished data).

532 However, both MAP gland spigots on the ALS and mAP gland spigots on the PMS were

533 significantly correlated with Instar (maximum number of instars within each species) (Table 2,

534 Table 5). This correlation with Instar is likely a case where having the full ontogeny incorporated

535 into an analysis would provide clarity on this odd result. In general, web builders tended to have

536 less number of instars to adulthood than non-web builders or wandering spiders; exceptions in

537 this study are the ambush thomisid and sit \& pursue (Miller et al., 2013) philodromid species:

538 Xysticus cristatus (C. Clerck, 1757) and Tibellus oblongus (C.A. Walckenaer, 1802), respectively

539 (Table S1), which had relatively few instars. Some second instars possess the two MAP gland

540 spigots observed in all species later in ontogeny. However, both X. cristatus and T. oblongus had

541 no MAP gland spigots in the second instar and Metellina segmentata (C. Clerck, 1757) possessed

542 only 1 MAP gland spigot (Table S1; Wąsowska, 1977; Yu \& Coddington, 1990; Townley \&

543 Tillinghast, 2009). These three species had some of the lower maximum numbers of instars per

544 species compared to the lycosoids, cribellate spiders and even viscous orb weavers (Table 2).

545 Second instars across species possessed either none, one or two mAP gland spigots and this

546 varied across foraging strategies and lineages. However, those species that possess both mAP

547 gland spigots at the second instar were consistently the species with a higher maximum number

548 of instars. This explains the significance of Instar as a predictor (Table S1).

\section{Ancestral character estimation:}

550 We also conducted an ancestral character estimation on specific spigots on the posterior lateral 551 spinneret whose potential homology have long been debated (Fig. 3; Peters, 1984; Peters, 1995;

552 Griswold et al., 2005; Eberhard, 2010; Eberhard \& Barrantes, 2015; R. Carlson \& C.E. Griswold, 553 unpublished data; R.E. Alfaro, unpublished data). We added an additional five species, including

554 two species sister to the Araneoids, and three cribellate species ancestral to both the Araneoidea 
555 and RTA clades (Fig. 3). As we previously described we constrained our rate matrix (Table 6)

556 that we used to model substitution rates across branch lengths based on prior knowledge about

557 historical possession of the flagelliform, pseudoflagelliform and modified spigots in each taxon

558 and considering Dollo's Law (Table 6) (Dollo, 1893; Platnick et al., 1991; Griswold et al., 2005;

559 Dimitrov et al., 2016; Wheeler et al., 2016).

560 The ancestral root of our phylogram of 27 species was more likely to have borne a

561 modified spigot or none at all (likelihood: 0.365, 0.635, respectively) (Fig. 3, Results S5).

562 Because this is not a full determination of the likelihood of a modified spigot or no spigot we

563 cannot definitively determine the character state of the orb weaving ancestor at the node where

564 Nicodamoidea + Araneoidea and the RTA clade split off (Fig. 3, Modified spigot likelihood:

5650.398 , None likelihood 0.602). It was unlikely to have possessed a pseudoflagelliform gland

566 spigot (Fig. 3, Pseudoflagelliform likelihood: 0.000). We can, therefore, hypothesize that

567 pseudoflagelliform and modified spigots are homologous structures and that modified spigots in

568 the RTA clade likely are retained structures like those found in the sister and ancestral cribellate

569 clades (Fig. 3). We cannot rule out that flagelliform gland spigots arose independently from

570 modified spigots and thus cannot infer homology between this spigot and the others. We do not

571 know the functionality of the modified spigots observed in D. tenebrosus and H. carolinensis.

572 This would be useful to explore in the future, as the functionality of modified spigots in cribellate

573 members of the RTA clade is the same as the pseudoflagelliform gland spigot (R.E. Alfaro et al.,

574 unpublished data). It is possible we are observing an intermediate stage of the loss of the

575 modified spigot in D. tenebrosus and H. carolinensis.

Our results may change if we can incorporate ontogeny into the ACE analysis. For

577 example, mimetids, which were ranked as having no spigots, do possess vestigial PLS spigots in

578 the early instars (Table S1, Townley \& Tillinghast, 2009). It is also possible that we are 
579 observing in real time the loss of the flagelliform gland spigot in this araneoid lineage. $T$.

580 perfuga possess primordial modified spigot and flankers in second instars prior to them

581 constructing webs in the third instar where functional spigots exist where the pre-spigots had

582 been (Table S1; R.E. Alfaro, unpublished data). In most species, the final molt of the adult male

583 leads to loss or nubbins (non-functional spigots) in all three: Modified, Pseudoflagelliform,

584 Flagelliform (Table S1; Wąsowska, 1977; Yu \& Coddington, 1990; Hajer, 1991; Townley \&

585 Tillinghast, 2009; Dolejš et al., 2014; R. Carlson \& C.E. Griswold, unpublished data). This

586 coincides with the male abandonment of the web for an alternative lifestyle of wandering in order

587 to find females.

$588 \quad$ Future work, as the methods of phylogenetic inference grow and progress, may yield

589 different results if we incorporate this analysis with the triad of spigots, i.e., the triplet of MS plus

590 flankers, PF and flankers and/or FL (flagelliform) plus AG (aggregate), or spigot associations, i.e.

591 PC with the PF in cribellate orb weavers. In araneoids, the flagelliform gland spigot is flanked by

592 two aggregate gland spigots and in T. perfuga the modified spigot is flanked by two spigots of

593 unknown gland association. In Tengella, these flankers resemble AC gland spigots but in some

594 other cribellate spiders, e.g., Matachia or Badumna (Griswold et al., 2005; figs 87 A, D) the

595 flankers resemble paracribellar (PC) gland spigots. The color-coded ACE phylogram shows a

596 trend of loss (black color) for all spigot types in approximately half of the tip species (Fig. 3).

597 This coincides with a shift in foraging strategies, i.e., from webs to running, observed in these

598 lineages (Table 2) and is consistent with the current hypothesis that an adaptive tradeoff between

599 silk production and fecundity is driving spider evolution to foraging strategies that do not involve

600 silk or web building (Blackledge et al., 2009). Given the recent conclusions of phylogenomics

601 studies indicating a much more ancient orb weaving ancestor and the new sister relationship of

602 cribellate orb weavers to the RTA clade, our ACE results do indicate that deeper and broader 
603 sampling across the spider tree of life is necessary (Bond et al., 2014; Fernández et al., 2014;

604 Garrison et al., 2014). performed for the independent variables of the PGLS analyses. Not surprisingly, given the results and discussion of the above analysis, the ancestral state at the root node of the phylogram of 27 species was Web builder for Strategy [foraging strategy; likelihood $=1.0$ ], and specifically either funnel $($ likelihood $=0.812)$, sheet $($ likelihood $=0.084)$ or orb webs $($ likelihood $=0.105)$

(Figs 9, 10). Also, given the ancestral state for the singular spigot on the PLS as Modified spigot (MS), one may reason that the ancestor was also a cribellate silk user. We found this to be the case after performing ACE on the independent variable Silk (main type of silk expressed), and found the ancestral state at the root of the phylogram was $100 \%$ likely to be cribellate (Fig 11).

614 Finally, Type or variety of spigot types, was less conclusive and we found likelihood values for 615 all states at the root node (Table S2). However, the most likely ancestral states were those 616 possessing a cribellum, paracribellum (likelihood $=0.398)$ and possibly a pseudoflagelliform 617 gland spigot $($ likelihood $=0.433)($ Fig 12). This may not actually conflict with our results for the 618 ACE of the singular PLS spigot, i.e., that MS is ancestral, in that we determined that the MS and 619 PF spigots are homologous structures. But we also found that the most likely state was no modified spigot $($ likelihood $=0.635)$, which would suggest the plesiomorphic state of cribellum + paracribellum, without any modifications of spigots on the PLS is the ancestral state at the root node of the ultrametric phylogram. to allow for a time-series dataset with multiple values per species, we suspect that incorporating the entire picture of spigot ontogeny will lead to some interesting and novel inferences about silk evolution. By not incorporating the entire ontogeny, but "snapshots" of the adult female and 
627 second instars, important observations are missed by the analyses, such as loss and regain of AC

628 gland spigots on the PLS in H. carolinensis, or presence of FL-AG triad spigots in early

629 Mimetidae instars. This approach to understanding spigot ontogeny from a phylogenetic

630 comparative perspective is novel and we can only build on our efforts from this study by growing

631 the dataset to include deeper taxon sampling and working towards the capability of phylogenetic

632 statistical analyses that can function to accommodate ontogeny datasets as whole units for each

633 species.

634 Conclusions:

635 In this study we explored spigot ontogeny in 22 species, including novel observations of

636 Dolomedes tenebrosus and Hogna carolinensis. This is the first effort to create a phylogenetic

637 comparative approach utilizing the recent Araneae Tree of Life. We performed 60 PGLS

638 analyses of five independent variables: Strategy, Specific, Silk Type, Instar and twelve dependent

639 variables (spigot numbers in adult females and second instars juveniles). Six had significant

640 correlation coefficients indicating Instar, Strategy and Type (spigot variety) as good predictors of

641 spigot numbers in spiders. Next, after adding five additional spider taxa to allow for deeper and

642 broader taxon sampling within the Araneomorphae, we reconstructed ancestral character

643 estimations of the unique, singular silk spigots on the PLS whose potential homology has been

644 debated. The analysis predicted the ancestral root to either have no singular spigot or to possess a

645 modified spigot (MS). Finally, additional ACE analyses on four of the five independent variables,

646 suggest that the ancestral root of the RTA clade and Araneoidea was likely a spider that was

647 cribellate, spun a web, and possessed a more diverse array of spigots. We also suggest that the

648 modified spigot (MS) and pseudoflagelliform gland spigots (PF) are homologous structures.

649 Current statistical methods do not allow for multiple values for species within PGLS, which 
650 limited our ontogenetic scope. However, as methods allow for more complex datasets, by

651 looking at the full picture of spigot morphology during a spider life cycle across multiple clades

652 of the AToL, we should be able to gain more depth of our understanding of silk evolution in 653 spiders.

654 Acknowledgements: The authors would like to thank Darrell Ubick and Erika Garcia for their 655 assistance at CAS with SEM specimen preparation and imaging of Dolomedes tenebrosus and 656 Hogna carolinensis. We wish to thank David Lightfoot and Kari Benson for donating the found 657 females used to start the lab colonies of each species, and Sami Cordova for collecting two 658 additional $H$. carolinensis females. We appreciate the conversations about spigot ontogeny of 659 lycosids and the willingness to share data and observations by Petr Dolejš. We also acknowledge 660 the work done by Robin Carlson to study the spigot ontogeny of the spinning apparatus of 661 Phyxelida tanganensis; her research was enabled by the CAS Summer Systematics Institute.

\section{References:}

663 Anderson JF. 1970. Metabolic rates of spiders. Comparative Biochemistry and Physiology 33:51-72. DOI: 10.1016/0010-406X(70)90483-4

665 Anderson JF. 1996. Metabolic rates of resting salticid and thomisid spiders. Journal of 666 Arachnology 24:129-134.

667 Anderson JF, Prestwich KN. 1982. Respiratory gas exchange in spiders. Physiological Zoology $668 \quad 55(1): 72-90$.

669 Barrantes G, Madrigal-Brenes R. 2008. Ontogenetic changes in web architecture and growth rate 670 of Tengella radiata (Araneae, Tengellidae). Journal of Arachnology 36:545-551.

671 DOI: $10.1636 / \mathrm{ST} 07-66.1$ 
672 Barrantes G, Eberhard WG. 2010. Ontogeny repeats phylogeny in Steatoda and Latrodectus

673 spiders. Journal of Arachnology 28:484-494. DOI: 10.1636/B10-05.1

674 Bartón K. 2016. MuMIn: Multi-model inference, R package version 1.15.6,

675 https://cran.r-https://cran.r-project.org/package=MuMIn .

676 Blackledge TA, Coddington JA, Agnarsson I. 2009. Fecundity increase supports adaptive

677 radiation hypothesis in spider web evolution. Communicative \& Integrative Biology 2:459-

678 463. DOI: $10.4161 /$ cib.2.6.8855

679 Blomberg SP, Garland T, Jr, Ives AR. 2003. Testing for phylogenetic signal in comparative data:

680 behavioral traits are more labile. Evolution 57(4):717-745.

681

DOI: 10.1554/0014-3820(2003)057[0717:TFPSIC]2.0.CO;2

682

Bond JE, Opell BD. 1998. Testing adaptive radiation and key innovation hypotheses in spiders.

$$
\text { Evolution 52(2):403-414. DOI: 10.1111/j.1558-5646.1998.tb01641.x }
$$

Bond JE, Garrison NL, Hamilton CA, Godwin RL, Hedin M, Agnarsson I. 2014. Phylogenomics

resolves a spider backbone phylogeny and rejects a prevailing paradigm for orb web

687 evolution. Current Biology 24:1-7. DOI: 10.1016/j.cub.2014.06.034

Coddington JA. 1986. The monophyletic origin of the orb web. In: Shear WA, ed. Spiders: Webs, Behavior and Evolution. Standford, CA: Stanford University Press, 319-363.

Coddington JA. 1989. Spinneret silk spigot morphology: Evidence for the monophyly of

Coddington JA. 1990. Cladistics and spider classification: araneomorph phylogeny and the monophyly of orbweavers (Araneae: Araneomorphae: Orbiculariae). Acta Zoologica Fenna 190:75-87.

Dimitrov D, Lopardo L, Giribet G, Arnedo MA, Álvarez-Padilla F, Hormiga G. 2012. Tangled in a sparse spider web: single origin of orb weavers and their spinning work unraveled by 
denser taxonomic sampling. Proceedings of the Royal Society B 279:1341-1350.

Dimitrov D, Benavides LR, Arnedo MA, Giribet G, Griswold CE, Scharff N, Hormiga G. 2016. Rounding up the usual suspects: a standard target-gene approach for resolving the interfamilial phylogenetic relationships of ecribellate orb-weaving spiders with a new family-rank classification (Araneae, Araneoidea). Cladistics 1-30. DOI: 10.1111/cla.12165.

Dolejš P, Buchar J, Kubcová L, Smrž J. 2014. Developmental changes in the spinning apparatus over the life cycle of wolf spiders (Araneae: Lycosidae). Invertebrate Biology 133(3):281297. DOI: $10.1111 /$ ivb. 12055

Dollo L. 1893. Les lois de l'évolution. Bulletin de la Société Belge de Géologie Paleont. Hydr.

712 patterns of change in web design in spiders. Psyche 92:105-118.

Eberhard WG. 1986. Ontogenetic changes in the web of Epeirotypus sp. (Araneae,

$$
7: 164-166 .
$$

Eberhard WG. 1985. The 'sawtoothed' orb of Eustala sp., with a discussion of the ontogenetic Theridiosomatidae). Journal of Arachnology 14:125-128.

Eberhard W, Pereira F. 1993. Ultrastructure of cribellate silk of nine species in eight families and possible taxonomic implications (Araneae: Amaurobiidae, Deinopidae, Desidae, Dictynidae, Filistatidae, Hypochilidae, Stiphidiidae, Tengellidae). Journal of Arachnology 21:161-174.

Eberhard W. 2010. Possible functional significance of spigot placement on the spinnerets of spiders. Journal of Arachnology 38:407-414. DOI: 10.1636/B09-97.1

Eberhard WG, Barrantes G. 2015. Cues guiding uloborid construction behavior support orb web monophyly. Journal of Arachnology 43:371-387. DOI: 10.1636/arac-43-03-371-387

Fernández R, Hormiga G, Giribet G. 2014. Phylogenomic analysis of spiders reveals nonmonophyly of orb weavers. Current Biology 24:1-6. DOI: 10.1016/j.cub.2014.06.035

Garb J. 2013. Spider silk: an ancient biomaterial of the $21^{\text {st }}$ century. In: Penney D, ed. Spider 
research in the $21^{\text {st }}$ century: trends and perspectives. Manchester, UK: Siri Scientific Press, 252-281.

724 Garrison NL, Rodriguez J, Agnarsson I, Coddington JA, Griswold CE, Hamilton CA, Hedin M, Kocot KM, Ledford JM, Bond JE. 2016. Spider phylogenomics: untangling the Spider Tree of Life. PeerJ 4: e1719. DOI: 10.7717/peerj.1719

Graber S. 2013. Phylogenetic comparative methods for discrete responses in evolutionary

Griswold CE. 1993. Investigations into the phylogeny of the lycosoids spiders and their kin (Arachnida: Araneae: Lycosoidea). Smithsonian Contributions to Zoology 539:1-39. DOI: $10.5479 /$ si.00810282.539

Griswold CE, Ramírez MJ, Coddington JA, Platnick NI. 2005. Atlas of phylogenetic data for entelegyne spiders (Araneae: Araneomorphae: Entelegynae) with comments on their phylogeny. Proceedings of the California Academy of Sciences 56:1-324.

Griswold CE, Ramírez MJ. 2017. Phylogeny of spiders. In: Ubick D, Paquin P, Cushing PE, eds. Spiders of North America: an identification manual. 2nd Edition, American Arachnological Society, 17-29.

Guo H, Weise RE, Gu X, Suchard MA. 2007. Time squared: Repeated measures on phylogenies. Molecular Biology and Evolution 24(2):353-362. DOI: 10.1093/molbev/ms1165

Hajer J. 1991. Notes on the spinning apparatus of the spiders Hyptiotes paradoxus C.L.K., 1834, and Uloborus walckenaerius Latr., 1806 (Araneae: Uloboridae). Bulletin de la Société des science naturelles de Neuchâtel 116(1):99-103. DOI: 10.5169/seals-89371

Harmon LJ, Weir JT, Brock CD, Glor RE, Challenger W. 2008. GEIGER: investigating evolutionary radiations. Bioinformatics 24:129-131. DOI: 10.1093/bioinformatics/btm538

Hawthorn AC, Opell BD. 2002. Evolution of adhesive mechanisms in cribellar spider prey capture thread: evidence for van der Waals and hygroscopic forces. Biological Journal of the 
748

Homann H. 1971. Die Augen der Araneae: Anatomie, Ontogenie und Bedeutung fur die Systematik (Chelicerata, Arachnida). Zeitschrift fur Morphologie der Tiere 69:201-272.

Hormiga G, Griswold GE. 2014. Systematics, phylogeny and evolution of orb weaving spiders. Annual Review of Entomology 59:487-512. DOI: 10.1146/annurev-ento-011613-162046

Maddison, WP, FitzJohn RG. 2015. The unsolved challenge to phylogenetic correlation tests for categorical characters. Systematic Biology 64(1):127-136. DOI: 10.1093/sysbio/syu070

Mallis RE, Miller KB. 2017. Natural history and courtship behavior in Tengella perfuga (Dahl 1901). Journal of Arachnology 45:166-176. DOI: 10.1636/15-004.1

Mathew EV, Sudhikumar A, Sebastian PA. 2011. Ultrastructural comparison of spinneret morphology of orb weaving and funnel web building spiders of Western Ghats, India. $26^{\text {th }}$ European Congress of Arachnology, Israel, Abstract book: 80.

Miller JRB, Ament JM, Schmitz OJ. 2014. Fear on the move: predator hunting mode predicts variation in prey mortality and plasticity in prey spatial response. Journal of Animal Ecology 83: 214-222. DOI: $10.1111 / 1365-2656.12111$

Pagel M. 1999. Inferring the historical patterns of biological evolution. Nature 401(6756):877884. DOI: $10.1038 / 44766$

Paradis E, Claude J, Strimmer K. 2004. APE: analyses of phylogenetics and evolution in R language. Bioinformatics 20:289-290. DOI: 10.1093/bioinformatics/btg412

Pechmann M, Khadjeh S, Sprenger F, Prpic N-M. 2010. Patterning mechanisms and morphological diversity of spider appendages and their importance for spider evolution. Arthropod Structure \& Development 39:453-467. DOI: 10.1016/j.asd.2010.07.007

Peters HM. 1984. The spinning apparatus of Uloboridae in relation to the structure and construction of capture threads (Arachnida, Araneida). Zoomorphology 104(2):96-104.

Peters HM. 1995. Polenecia producta and its web: structure and evolution (Araneae, 
Uloboridae). Zoomorphology 115(1):1-9.

773 Pinheiro J, Bates D, DebRoy S, Sarkar D, R Core Team. 2017. nlme: Linear and non-linear

$774 \quad$ mixed effects models. R package version 3.1-131.

775

https://CRAN.R-project.org/package=nlme

776 Platnick NI. 1977. The hypochiloid spiders: a cladistic analysis, with notes on the Atypoidea

777 (Arachnida, Araneae). American Museum Novitates 2627:1-23.

778 Platnick NI. 1990. Spinneret morphology and the phylogeny of ground spiders (Araneae, 779 Gnaphosoidea). American Museum Novitates 2978:1-42.

780 Platnick NI., Coddington JA, Forster RF, Griswold CE. 1991. Spinneret morphology and the

781 higher classification of the haplogyne spiders (Araneae, Araneomorphae). American $782 \quad$ Museum Novitates 3016:1-73.

783 Polotow D, Carmichael A, Griswold CE. 2015. Total evidence analyses of the phylogenetic

784 relationships of Lycosoidea spiders (Araneae, Entelegynae). Invertebrate Systematics 29:124-163. DOI: 10.1071/IS14041

Prestwich KN. 1977. The energetics of web-building in spiders. Comparative Biochemistry and Physiology 57A:321-326. DOI: 10.1016/0300-9629(77)90199-2

788 Prestwich KN. 1983. The roles of aerobic and anaerobic metabolism in active spiders. Physiological Zoology 56(1):122-132. DOI: 10.1086/physzool.56.1.30159973

R Core Team. 2016. R: A language and environment for statistical computing. R Foundation for Statistical Computing, Vienna, Austria https://www.R-project.org.

RStudio. 2017. RStudio: Integrated development environment for R [Computer software]. Boston, MA. Retrieved February 22, 2017. http://www.rstudio.org.

Ramírez MJ. 2014. The morphology and phylogeny of dionychan spiders (Araneae:

795 Araneomorphae). Bulletin of the American Museum of Natural History 390:1-374. DOI: $10.1206 / 821.1$ 
797 Revell LJ. 2012. phytools: An R package for phylogenetic comparative biology (and other 798 things). Methods in Ecology and Evolution 3:217-233.

DOI: 10.1111/j.2041-201X.2011.00169.X

800

801

802

803

804

805

806

807

808

809

810

811

812

814

815

816

817

818

819

820

Robinson MH, Lubin YD. 1979. Specialists and generalists: the ecology and behavior of some web-building spiders from Papua New Guinea. II. Psechrus argentatus and Fecenia sp. (Araneae: Psechridae). Pacific Insects 21:133-164.

Schmitz OJ, Suttle KB. 2001. Effects of top predator species on direct and indirect interactions in a food web. Ecology 82:2072-2081. DOI: 10.1890/0012-9658

Selden PA, Shear WA, Sutton MD. 2008. Fossil evidence for the origin of spider spinnerets, and a proposed arachnid order. PNAS 105(52):20781-20785. DOI: 10.1073/pnas.0809174106

Townley MA, Tillinghast EK. 2009. Developmental changes in spider spinning fields: a comparison between Mimetus and Araneus (Araneae: Mimetidae, Araneidae). Biological Journal of the Linnaean Society 98:343-383. DOI: 10.1111/j.1095-8312.2009.01297.x

Wąsowska S. 1977. Studies on the spinning apparatus in spiders. Postembryonic morphogeny of the spinning apparatus. Zoologica Poloniae 26(3-4):355-407.

Wheeler WC, Coddington JA, Crowley LM, Dimitrov D, Goloboff PA, Griswold CE, Hormiga G, Prendini L, Ramírez MJ, Sierwald P, Almeida-Silva L, Alvarez-Padilla F, Arnedo MA, Benavides Silva LR, Benjamin SP, Bond JE, Grismado CJ, Hasan E, Hedin M, Izquierdo MA, Labarque FM, Piacentini LN, Platnick NI, Polotow D, Silva-Dávila D, Scharff N, Szütz T, Ubick D, Vink CJ, Wood HM, Zhang J. 2016. The spider tree of life: phylogeny of Araneae based on target-gene analyses from an extensive taxon sampling. Cladistics (0):143. DOI: $10.1111 /$ cla.12182

Yu L, Coddington JA. 1990. Ontogenetic changes in the spinning fields of Nuctenea cornuta and Neoscona theisi (Araneae, Araneidae). Journal of Arachnology 18:331-345. 


\section{Table $\mathbf{1}$ (on next page)}

Full spigot ontogeny of Dolomedes tenebrosus and Hogna carolinensis.

Numbers of functional spigots by spinneret for each instar. Pre-spigots are noted for those whose functionality is determined. * Indicates a tentative identification which requires more replicates to confirm. 


\begin{tabular}{|c|c|c|c|c|c|c|c|c|c|}
\hline \multirow[b]{3}{*}{ Species } & \multirow[b]{3}{*}{ Instar } & \multicolumn{8}{|c|}{ Spinneret } \\
\hline & & \multicolumn{2}{|c|}{ ALS } & \multicolumn{3}{|c|}{ PMS } & \multicolumn{3}{|c|}{ PLS } \\
\hline & & MAP & PI & $\mathbf{m A P}$ & $\mathbf{A C}$ & CY & $\mathbf{A C}$ & CY & Modified \\
\hline Dolomedes tenebrosus & 2 & 2 & 6 & 2 & 4 & 0 & 4 & 0 & 0 \\
\hline Hogna carolinensis & 2 & 2 & 4 & 2 & 4 & 0 & 7 & 0 & 0 \\
\hline Dolomedes tenebrosus & 3 & 2 & 9 & 2 & 4 & 0 & 6 & 0 & 0 \\
\hline Hogna carolinensis & 3 & 2 & 7 & 2 & 6 & 0 & 9 & 0 & 0 \\
\hline Dolomedes tenebrosus & 4 & 2 & 9 & 2 & 5 & 0 & 6 & 0 & 0 \\
\hline Hogna carolinensis & 4 & 2 & 11 & 2 & 3 & 0 & 3 & 0 & 0 \\
\hline Dolomedes tenebrosus & 5 & 2 & 14 & 2 & 5 & 0 & 6 & 0 & 0 \\
\hline Hogna carolinensis & 5 & 2 & 13 & 2 & 3 & 0 & 3 & 0 & 0 \\
\hline Dolomedes tenebrosus & 6 & 2 & 16 & 2 & 5 & 0 & 9 & 0 & 0 \\
\hline Hogna carolinensis & 6 & 2 & 17 & 2 & 6 & 0 & 7 & 0 & 0 \\
\hline Dolomedes tenebrosus & 7 & 2 & 18 & 2 & 6 & 0 & 8 & 0 & 0 \\
\hline Hogna carolinensis & 7 & 2 & 27 & 2 & 4 & 0 & 7 & 0 & 0 \\
\hline Dolomedes tenebrosus & 8 & 2 & 27 & 2 & 8 & 0 & 9 & 0 & 0 \\
\hline Dolomedes tenebrosus & 9 & 2 & 57 & 2 & 8 & 0 & 15 & 0 & 0 \\
\hline Dolomedes tenebrosus & 10 antepen- + & 2 & 52 & 2 & 8 & 0 & 10 & 0 & 0 \\
\hline Dolomedes tenebrosus & 11 pen-ổ & 2 & 75 & 2 & 9 & 0 & 14 & 0 & 0 \\
\hline Dolomedes tenebrosus & 12 pen-우 & 2 & 133 & 2 & 30 & Pre1 & 42 & Pre3 & Pre1 \\
\hline Dolomedes tenebrosus & $12 \hat{O}^{-1}$ & 1 & 54 & 1 & 7 & 0 & 13 & 0 & 0 \\
\hline Hogna carolinensis & 12 운 & 2 & 122 & 2 & 82 & 10 & 43 & 1 & $1^{*}$ \\
\hline Dolomedes tenebrosus & 13 웅 & 2 & 107 & 2 & 15 & 32 & 24 & 28 & 1 \\
\hline
\end{tabular}




\section{Table 2 (on next page)}

Species included in PGLS analyses by spider family.

Twenty-two species across thirteen spider families were used in the PGLS analyses. The scoring for the five independent variables, from Foraging Strategy to Maximum Number of Instars is reported here. 'Strategy' delineates web (0) or no web usage (1). 'Specific' refers to the type of prey pursuit (1-3) or web (4-5) used by each species. 'Silk' quantifies the main type of silk used by each species from aciniform (1) to viscous (4). 'Type' is a numerical designation for the variety of silk spigot types each species possesses from the 'standard 7 ' (1) to standard 7 + paracribellar + cribellum + pseudoflagelliform (4). Finally, 'Instar' refers to the maximum number of instars reported for adult females of each species. 


\begin{tabular}{|c|c|c|c|c|c|c|}
\hline Family & Species & Strategy & Specific & Silk & Type & Instar \\
\hline Philodromidae & Tibellus oblongus & 1 & 2 & 1 & 1 & 6 \\
\hline Thomisidae & Xysticus cristatus & 1 & 1.5 & 1 & 1 & 6 \\
\hline \multirow[t]{6}{*}{ Lycosidae } & Xerolycosa nemoralis & 1 & 3 & 1 & 1 & 10 \\
\hline & Pardosa lugubris & 1 & 3 & 1 & 1 & 7 \\
\hline & Pardosa amentata & 1 & 3 & 1 & 1 & 9 \\
\hline & Hogna carolinensis & 1 & 2 & 1 & 2 & 12 \\
\hline & Arctosa lutetiana & 1 & 1.5 & 1.5 & 1 & 9 \\
\hline & Arctosa alpigena lamperti & 1 & 3 & 1 & 1 & 10 \\
\hline Pisauridae & Dolomedes tenebrosus & 1 & 1 & 1 & 2 & 13 \\
\hline Zoropsidae & Tengella perfuga & 0 & 4.5 & 3 & 2.5 & 12 \\
\hline Dictynidae & Argyroneta aquatica & 0 & 4 & 2 & 1 & 6 \\
\hline Agelenidae & Eratigena atrica & 0 & 4.5 & 2 & 1 & 9 \\
\hline Phyxelididae & Phyxelida tanganensis & 0 & 4 & 3 & 4 & 8 \\
\hline Uloboridae & Hyptiotes paradoxus & 0 & 5 & 3 & 4 & 6 \\
\hline Tetragnathidae & Metellina segmentata & 0 & 5 & 4 & 3 & 5 \\
\hline \multirow[t]{2}{*}{ Mimetidae } & Mimetus puritanus & 1 & 2.5 & 1 & 1.5 & 7 \\
\hline & Mimetus notius & 1 & 2.5 & 1 & 1.5 & 7 \\
\hline \multirow[t]{4}{*}{ Araneidae } & Neoscona theisi & 0 & 5 & 4 & 3 & 7 \\
\hline & Araneus cavaticus & 0 & 5 & 4 & 3 & 12 \\
\hline & Araneus diadematus & 0 & 5 & 4 & 3 & 10 \\
\hline & Larinioides cornutus & 0 & 5 & 4 & 3 & 7 \\
\hline Theridiidae & Enoplognatha ovata & 0 & 5.5 & 4 & 3 & 4 \\
\hline
\end{tabular}




\section{Table 3(on next page)}

Results of tests for phylogenetic signal.

Results of the tests for phylogenetic signal using Pagel's $\lambda$ and Blomberg's $K$ for all independent and dependent variables. Those with significant phylogenetic signal are bolded and include all independent variables and three of the response variables. 


\begin{tabular}{llcccc} 
& Variable & Pagel's $\boldsymbol{\lambda}$ & P-value & Blomberg's & P-value \\
\hline (I) & Strategy & $\mathbf{1 . 0 0 0}$ & $\mathbf{0 . 0 0 0 6}$ & $\mathbf{0 . 9 5 5}$ & $\mathbf{0 . 0 0 1}$ \\
(I) & Specific & $\mathbf{1 . 0 0 0}$ & $\mathbf{0 . 0 0 2}$ & $\mathbf{0 . 9 0 4}$ & $\mathbf{0 . 0 0 2}$ \\
(I) & Silk & $\mathbf{1 . 0 0 0}$ & $\mathbf{0 . 0 0 0 3}$ & $\mathbf{0 . 9 1 5}$ & $\mathbf{0 . 0 0 1}$ \\
(I) & Type & $\mathbf{1 . 0 0 0}$ & $\mathbf{0 . 0 0 0 0 8}$ & $\mathbf{1 . 2 4 3}$ & $\mathbf{0 . 0 0 1}$ \\
(I) & Instar & 0.565 & 0.139 & $\mathbf{0 . 5 1 2}$ & $\mathbf{0 . 0 1 2}$ \\
(D) & Fem ALS MAP & $\mathbf{1 . 0 0 0}$ & $\mathbf{0 . 0 0 0 0 4}$ & $\mathbf{0 . 6 3 4}$ & $\mathbf{0 . 0 0 9}$ \\
(D) & Fem ALS PI & 0.110 & 0.698 & 0.158 & 0.795 \\
(D) & Fem PMS mAP & $\mathbf{1 . 0 0 0}$ & $\mathbf{5 . 3 6} \mathbf{e}^{-10}$ & $\mathbf{3 . 8 3 4}$ & $\mathbf{0 . 0 0 2}$ \\
(D) & Fem PMS AC & 0.532 & 0.210 & 0.176 & 0.769 \\
(D) & Fem PMS CY & 0.229 & 0.141 & 0.452 & 0.076 \\
(D) & Fem PLS AC & 0.572 & 0.270 & 0.184 & 0.731 \\
(D) & Fem PLS CY & 0.057 & 0.698 & 0.315 & 0.243 \\
(D) & 2nd ALS MAP & $6.61 \mathrm{E}-05$ & 1.000 & 0.313 & 0.287 \\
(D) & 2nd ALS PI & 0.076 & 0.603 & 0.093 & 0.877 \\
(D) & 2nd PMS mAP & $\mathbf{1 . 0 0 0}$ & $\mathbf{0 . 0 0 2}$ & $\mathbf{0 . 7 9 4}$ & $\mathbf{0 . 0 0 8}$ \\
(D) & 2nd PMS AC & $6.61 \mathrm{E}-05$ & 1.000 & 0.084 & 0.871 \\
(D) & 2nd PLS AC & $6.61 \mathrm{E}-05$ & 1.000 & 0.081 & 0.895
\end{tabular}




\section{Table 4 (on next page)}

Significant results of Model Selection for PGLS analyses.

Model selection results for selected single-term PGLS models, showing Instar as most important and the model selection as significant. $\mathrm{AIC}_{\mathrm{C}}$ and $\triangle \mathrm{AIC}_{\mathrm{C}}$ values for model selection for all independent variables, by response variable. Term codes are: Instar $=1$, Type $=2$, Silk $=3$, Specific $=4$, Strategy $=5$. Significant results are bolded, if not significant, but most important term, they are bold italicized. 
1

$22^{\text {nd }}$ Instar ALS MAP Model Selection:

Female ALS Piriform Model Selection:

$\begin{array}{cccc}\text { Term } & \mathbf{A I C}_{\mathbf{C}} & \boldsymbol{\Delta} & \text { Weight } \\ \text { Instar } & \mathbf{4 3 . 3 5} & \mathbf{0 . 0 0} & \mathbf{0 . 8 4} \\ \text { Strategy } & 48.75 & 5.40 & 0.06 \\ \text { Type } & 49.32 & 5.97 & 0.04 \\ \text { Specific } & 49.35 & 5.99 & 0.04 \\ \text { Silk } & 50.57 & 7.21 & 0.02\end{array}$

3

$4 \quad 2^{\text {nd }}$ Instar ALS Piriform Model Selection:

$\begin{array}{cccc}\text { Term } & \text { AIC }_{\mathbf{C}} & \boldsymbol{\Delta} & \text { Weight } \\ \boldsymbol{1} & \mathbf{2 0 5 . 3 1} & \mathbf{0 . 0 0} & \mathbf{0 . 3 7} \\ 3 & 206.80 & 1.49 & 0.18 \\ 5 & 207.03 & 1.72 & 0.16 \\ 4 & 207.13 & 1.82 & 0.15 \\ 2 & 207.15 & 1.83 & 0.15\end{array}$

Female PLS Aciniform Selection:

$\begin{array}{cccc}\text { Term } & \text { AIC }_{\mathbf{C}} & \boldsymbol{\Delta} & \text { Weight } \\ \mathbf{1} & \mathbf{2 5 1 . 9 5} & \mathbf{0 . 0 0} & \mathbf{0 . 9 1} \\ 4 & 259.03 & 7.08 & 0.03 \\ 5 & 259.18 & 7.23 & 0.02 \\ 3 & 259.58 & 7.62 & 0.02 \\ 2 & 259.83 & 7.88 & 0.02\end{array}$

6 Female PMS Aciniform Model Selection:

$\begin{array}{cccc}\text { Term } & \mathbf{A I C}_{\mathbf{C}} & \boldsymbol{\Delta} & \text { Weight } \\ \mathbf{1} & \mathbf{2 5 8 . 0 4} & \mathbf{0 . 0 0} & \mathbf{0 . 9 8} \\ 2 & 268.36 & 10.32 & 0.01 \\ 5 & 268.51 & 10.47 & 0.01 \\ 3 & 268.70 & 10.66 & 0.00 \\ 4 & 268.74 & 10.70 & 0.00\end{array}$

7 


\section{Table 5 (on next page)}

Significant results of PGLS analyses.

Significant results of the phylogenetic generalized least squares analyses testing for correlation of independent variables with the twelve dependent variables (average number of each standard spigot) for both adult female datasets and second instar datasets. The coefficient values provide the correlation coefficient of the means of the independent variable with the dependent variable. 
1

\begin{tabular}{|ccc|}
\hline \multicolumn{3}{|c|}{ Second Instar ALS MAP } \\
Model: Average $\sim$ Instar \\
PGLS Coefficient: & $\mathbf{t}$ & $\mathbf{P}$ \\
Instar $\quad 0.095$ & 2.283 & 0.034 \\
\hline
\end{tabular}

\begin{tabular}{|ccc|}
\hline \multicolumn{3}{|c|}{ Second Instar PMS mAP } \\
Model: Average $\sim$ Instar \\
PGLS Coefficient: & $\mathbf{t}$ & $\mathbf{P}$ \\
Instar $\quad 0.104$ & 2.641 & 0.016 \\
\hline
\end{tabular}

\begin{tabular}{|c|c|c|c|}
\hline \multicolumn{4}{|c|}{ Female PMS mAP } \\
\hline \multicolumn{4}{|c|}{ Model: Average $\sim$ Strategy } \\
\hline \multicolumn{2}{|c|}{ PGLS Coefficient: } & $\mathbf{t}$ & $\mathbf{P}$ \\
\hline Strategy & 0.291 & 2.448 & 0.024 \\
\hline
\end{tabular}

\begin{tabular}{|ccc|}
\hline \multicolumn{4}{|c|}{ Female ALS Piriform } \\
Model: Average $\sim$ Instar \\
PGLS Coefficient: & \multicolumn{1}{c}{} \\
Instar $\quad 17.204$ & 5.355 & $<0.000$ \\
Model: Average $\sim$ Type & & \\
PGLS Coefficient: & $\mathbf{t}$ & $\mathbf{P}$ \\
Type $\quad 61.692$ & 4.413 & 0.0003 \\
\hline
\end{tabular}

Female PMS Aciniform

Model: Average $\sim$ Instar

\begin{tabular}{crcc}
\multicolumn{2}{c}{ PGLS Coefficient: } & $\mathbf{t}$ & $\mathbf{P}$ \\
Instar & 11.725 & 2.857 & 0.010 \\
\hline
\end{tabular}

2 


\section{Table 6(on next page)}

Evolutionary rate matrix for ACE of unique PLS spigots.

The substitution rate matrix for the spigots of the PLS used as the model for the ancestral character estimation analysis. The rows are the from direction, while the columns are the to direction for state changes. 
1

\begin{tabular}{cccccc} 
SPIGOT & Flagelliform & Loss & Modified & None & Pseudoflage \\
\hline Flagelliform & -- & 1 & 0 & 0 & 0 \\
Loss & 0 & -- & 0 & 0 & 0 \\
Modified & 1 & 1 & -- & 1 & 1 \\
None & 1 & 0 & 1 & -- & 1 \\
Pseudoflagelliform & 1 & 1 & 0 & 0 & --
\end{tabular}

2 


\section{Figure 1}

Scanning electron micrographs of a spider spinning apparatus morphology.

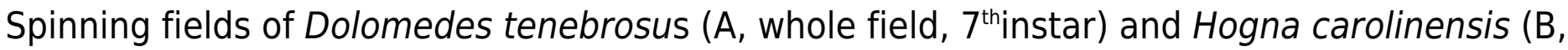
right field, $4^{\text {thinstar}) . ~ A L S ~}=$ Anterior lateral spinnerets, $\mathrm{PMS}=$ Posterior median spinnerets, PLS $=$ Poster lateral spinnerets.

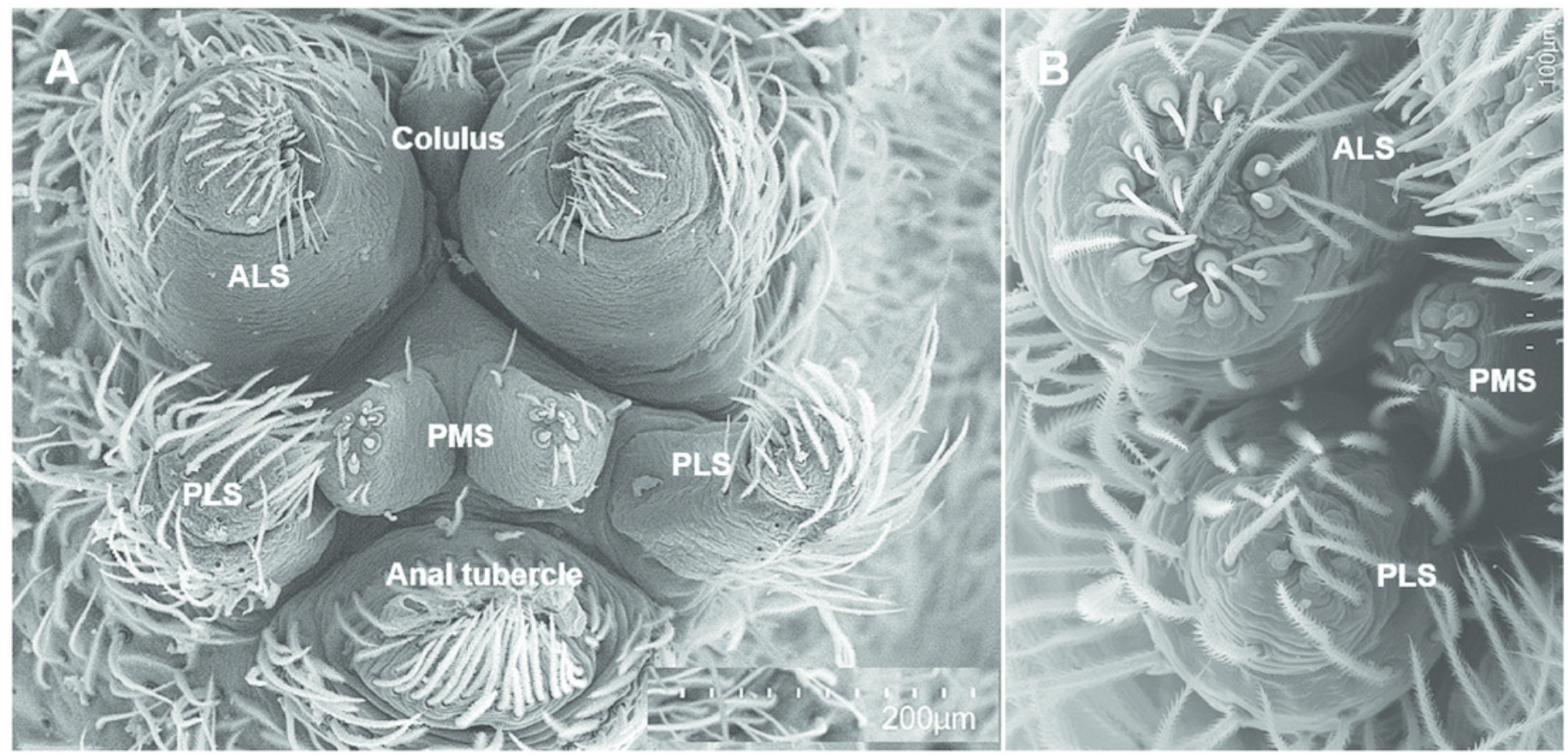


Figure 2

Phylogenetic tree used in PGLS analyses.

Ultrametric tree with 22 species, topology follows the AToL (Wheeler et al. 2016).

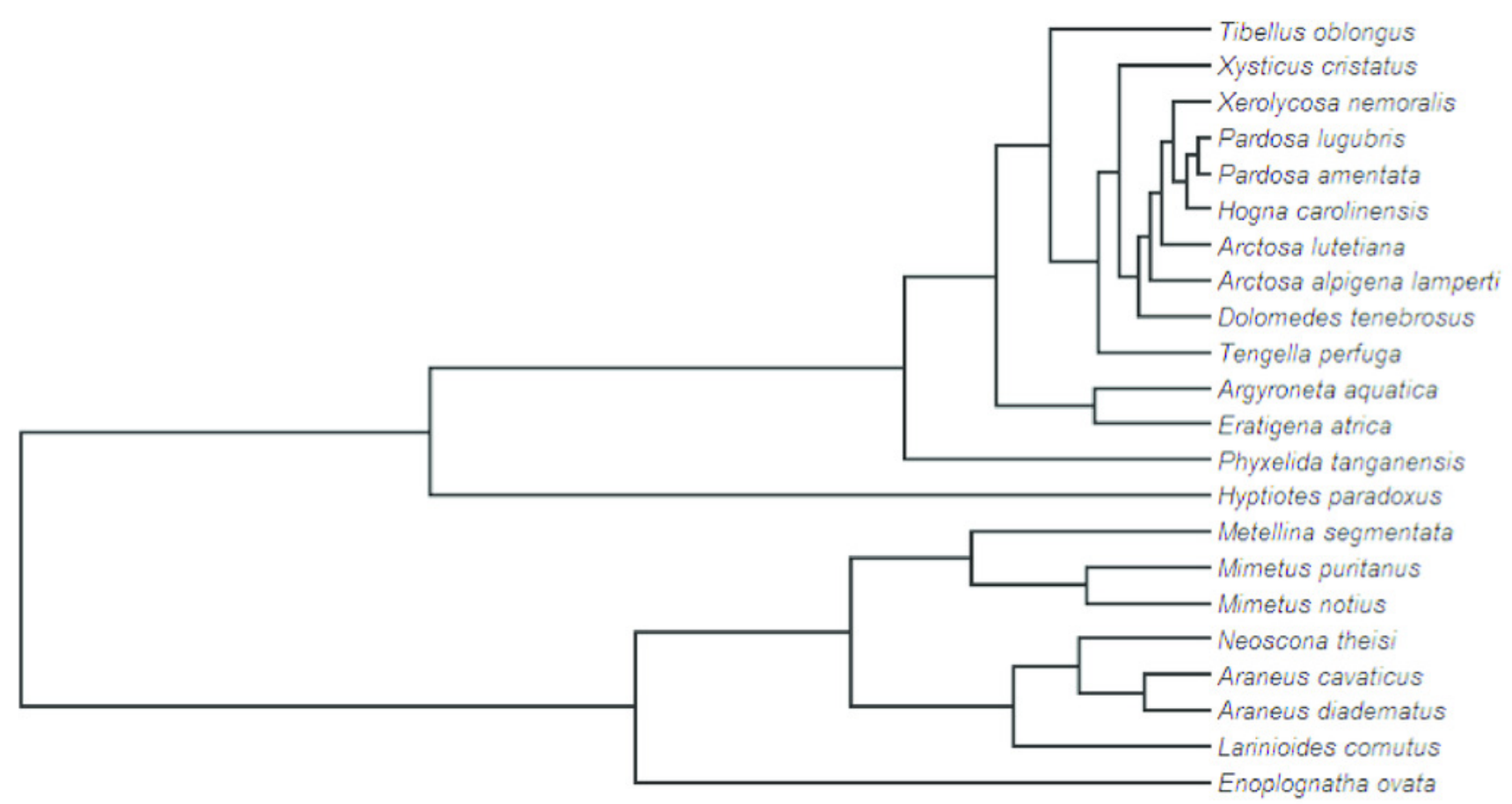




\section{Figure 3}

\section{Ancestral character estimation results for the unique PLS spigots.}

Phylogram with ancestral character estimation of singular PLS spigots on the ultrametric tree with five additional taxa. The root node is estimated to either possess a modified spigot (green) or no specialized spigots (blue).

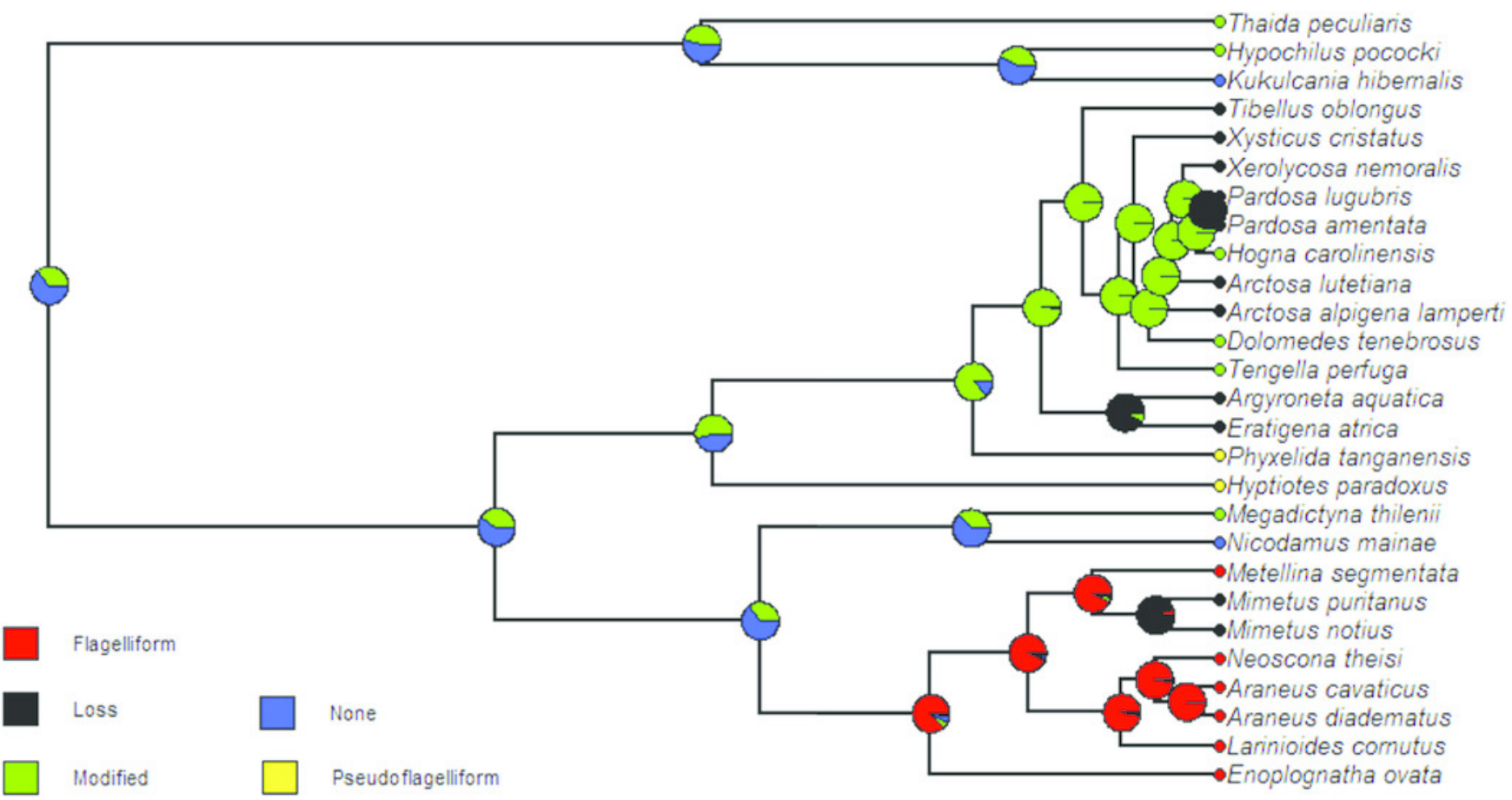




\section{Figure 4}

SEMs of the anterior lateral spinnerets.

ALS spinning field of selected instars of Dolomedes tenebrosus and Hogna carolinensis: A: $D$. tenebrosus $3^{\text {rd }}$ instar left ALS; B: H. carolinensis $4^{\text {th }}$ instar (left ALS); C. H. carolinensis $5^{\text {th }}$ instar (left ALS); D. D. tenebrosus $8^{\text {th }}$ instar (left ALS); E. D. tenebrosus $12^{\text {th }}$ instar (right ALS, penultimate female). MAP = Major ampullate gland spigot.

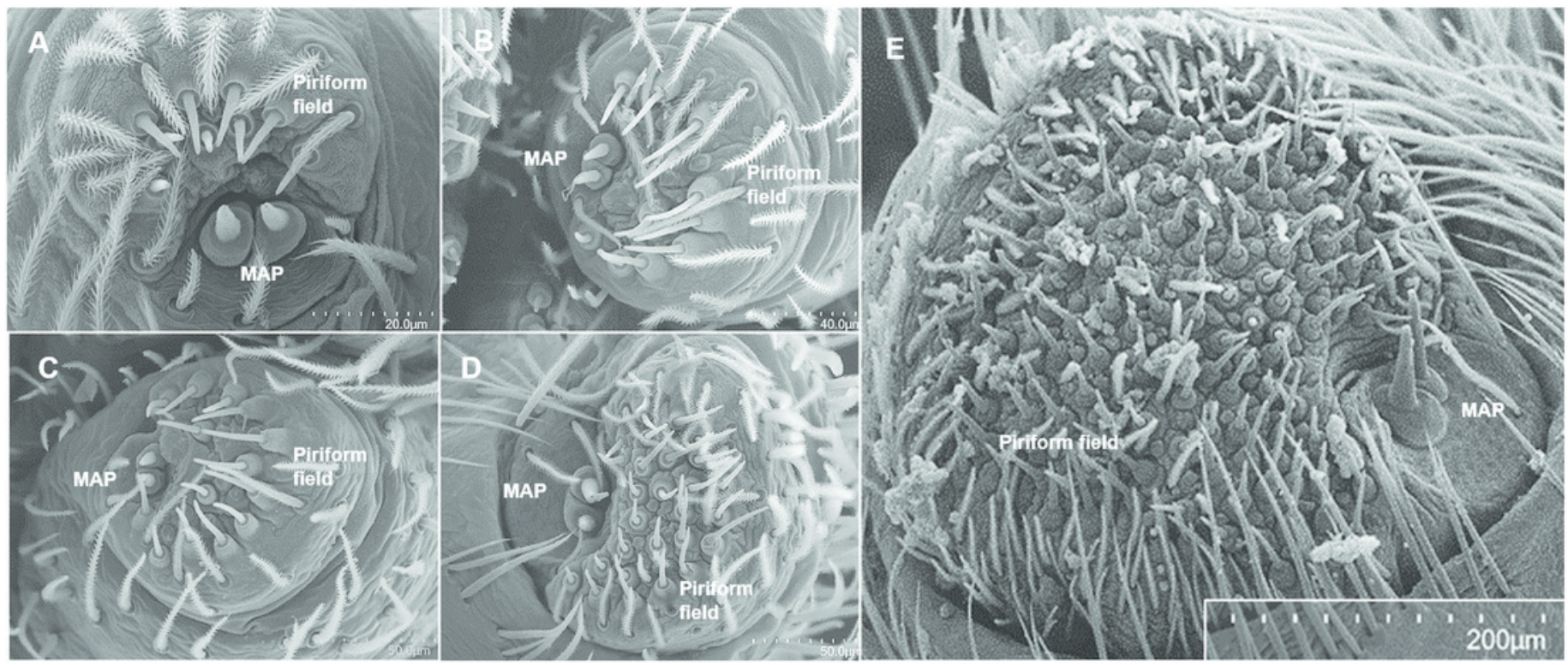




\section{Figure 5}

SEMs of the sensilla of the anterior lateral spinnerets.

Pore field of the MAP on the ALS of selected instars of Dolomedes tenebrosus and Hogna carolinensis: A. H. carolinensis $3^{\text {rd }}$ instar (left ALS); B. H. carolinensis $5^{\text {th }}$ instar (left ALS); C. D. tenebrosus $11^{\text {th }}$ instar (penultimate male, left ALS); D. D. tenebrosus $12^{\text {th }}$ instar (penultimate female, right ALS). MAP = Major ampullate gland spigot, Sensilla $=$ sensory pores in MAP field.

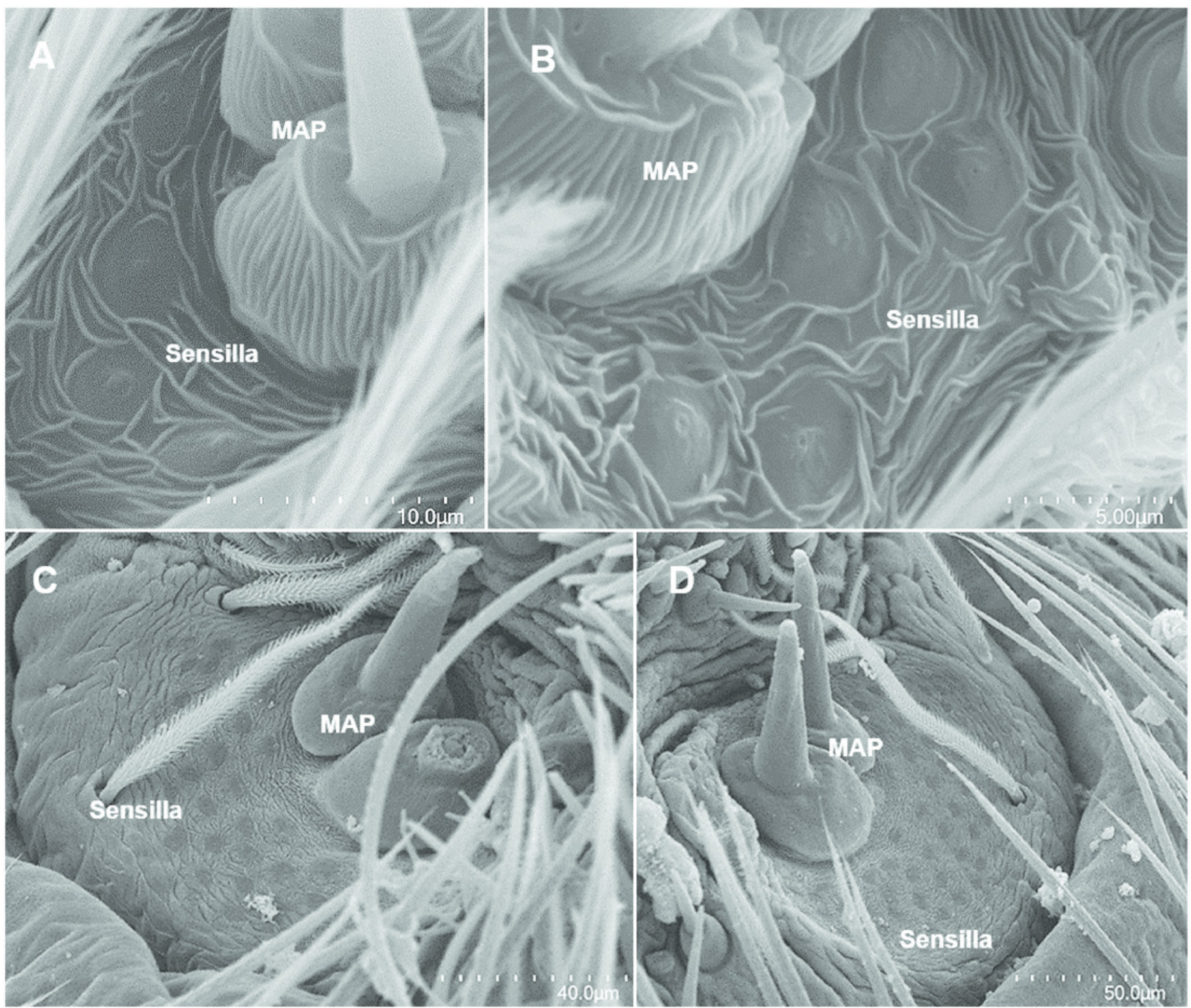




\section{Figure 6}

SEMs of the posterior median spinnerets.

PMS spinning field of selected instars of Dolomedes tenebrosus and Hogna carolinensis: A. $H$. carolinensis $2^{\text {nd }}$ instar (left PMS); B. H. carolinensis $6^{\text {th }}$ instar (right PMS); C. H. carolinensis $12^{\text {th }}$ instar, female (left PMS); D. D. tenebrosus $3^{\text {rd }}$ instar (left PMS); E. D. tenebrosus $5^{\text {th }}$ instar (right PMS); F. D. tenebrosus $12^{\text {th }}$ instar, penultimate female (right PMS). mAP $=$ Minor ampullate gland spigot, Pre-CY = pre-cylindrical gland spigot.
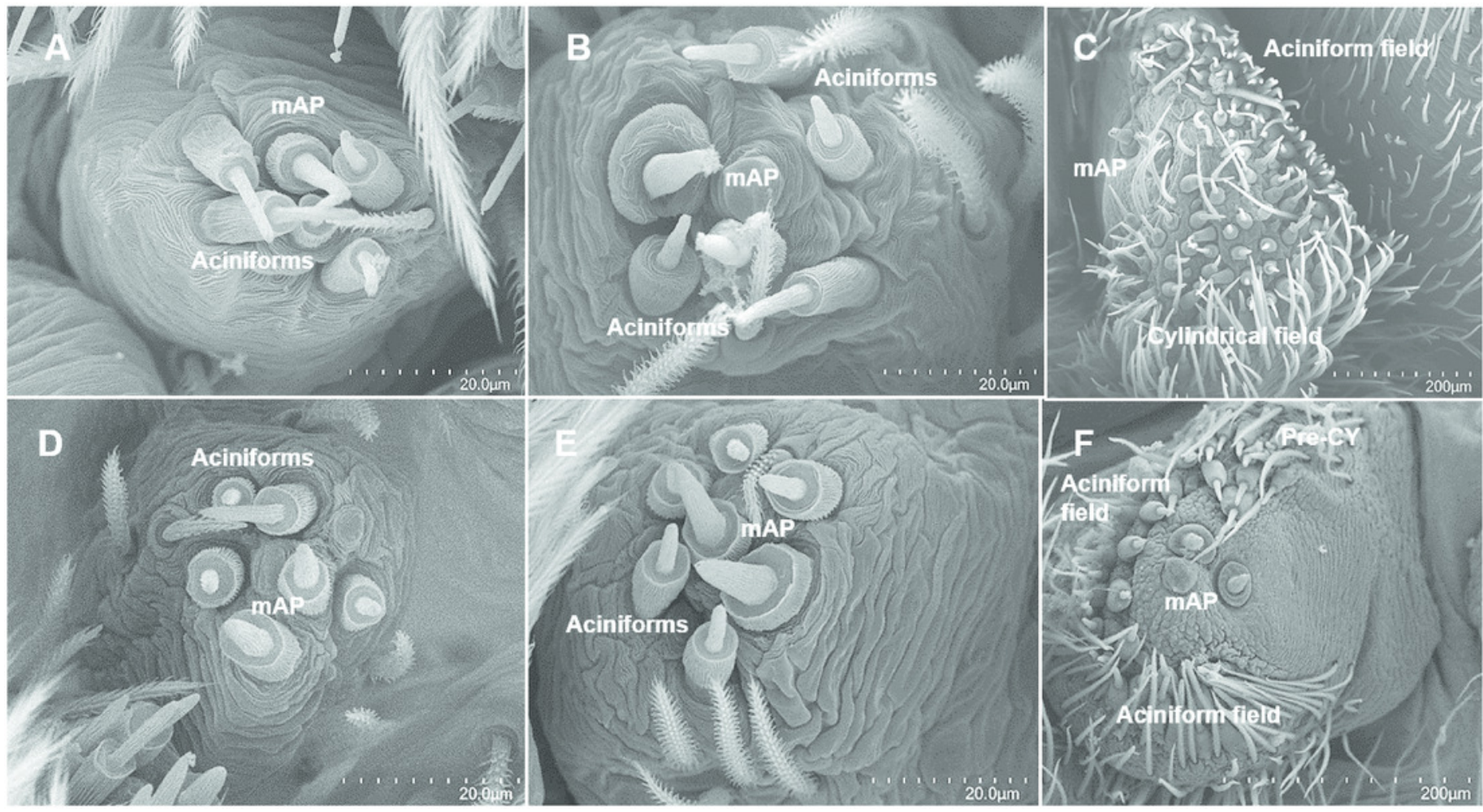


\section{Figure 7}

SEMs of the posterior lateral spinneret spigots of Dolomedes tenebrosus.

PLS spinning field of selected instars of Dolomedes tenebrosus, early instars have low conserved numbers of aciniform gland spigots, which suddenly increase at the penultimate instar: A. $3^{\text {rd }}$ instar (left PLS); B. $4^{\text {th }}$ instar (right PLS); C. $6^{\text {th }}$ instar (left PLS); D. 8th instar (left PLS); E. $10^{\text {th }}$ instar, antepenultimate female (left PLS); F. $12^{\text {th }}$ instar, penultimate female (left PLS). Pre-CY = Pre-cylindrical gland spigots, Pre-Mod = Pre-Modified spigot.

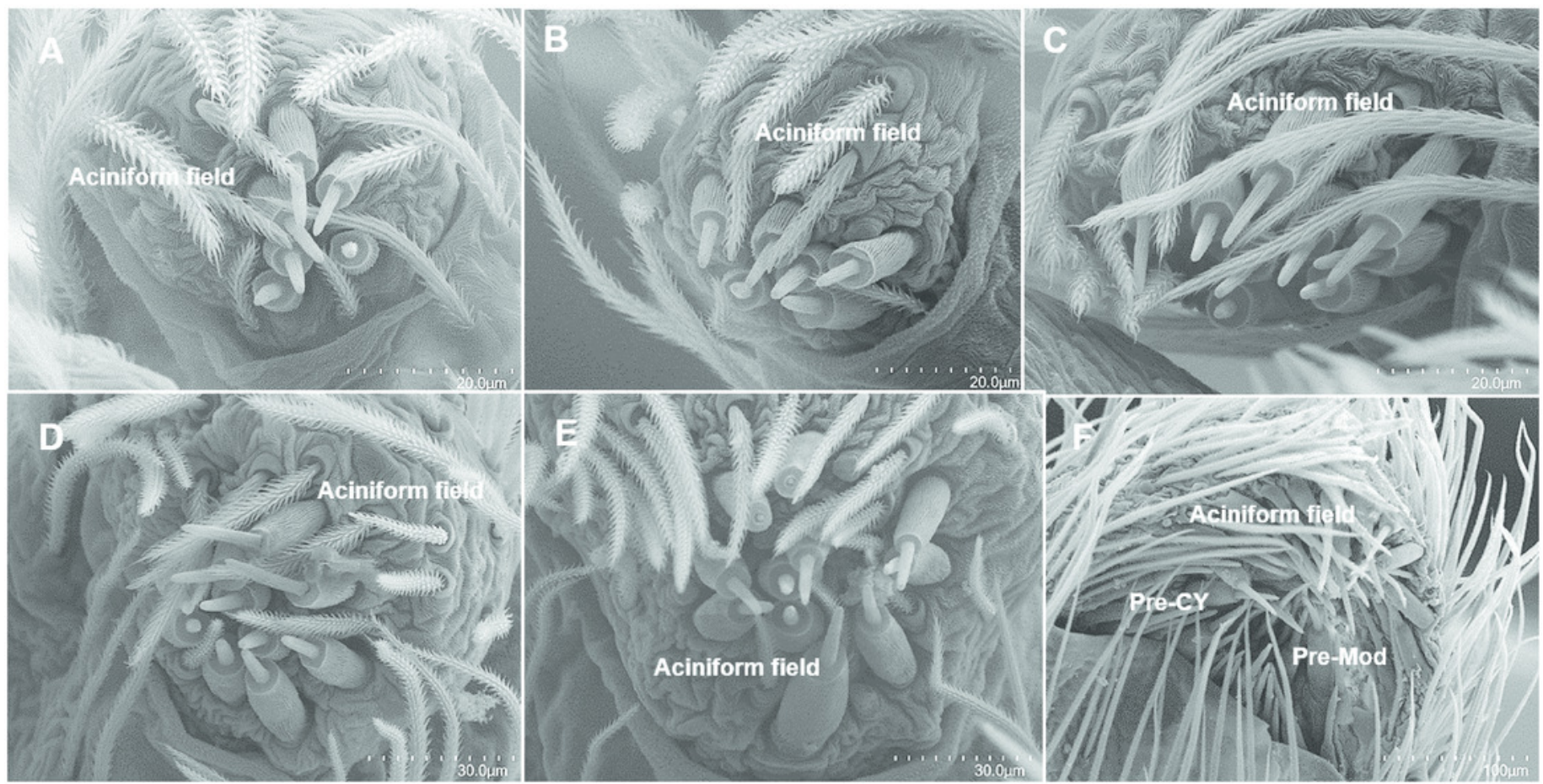




\section{Figure 8}

SEMs of the posterior lateral spinneret spigots of Hogna carolinensis.

Right PLS spinning field of selected instars of Hogna carolinensis, early instars have higher numbers of aciniform gland spigots, lose them over two molts, then begin to gain them back again: A. $2^{\text {nd }}$ instar; B. $3^{\text {rd }}$ instar; C. $4^{\text {th }}$ instar; D. $5^{\text {th }}$ instar; E. $6^{\text {th }}$ instar. Aciniform tartipores $=$ cuticular scars from aciniform gland spigots present in the previous instar.

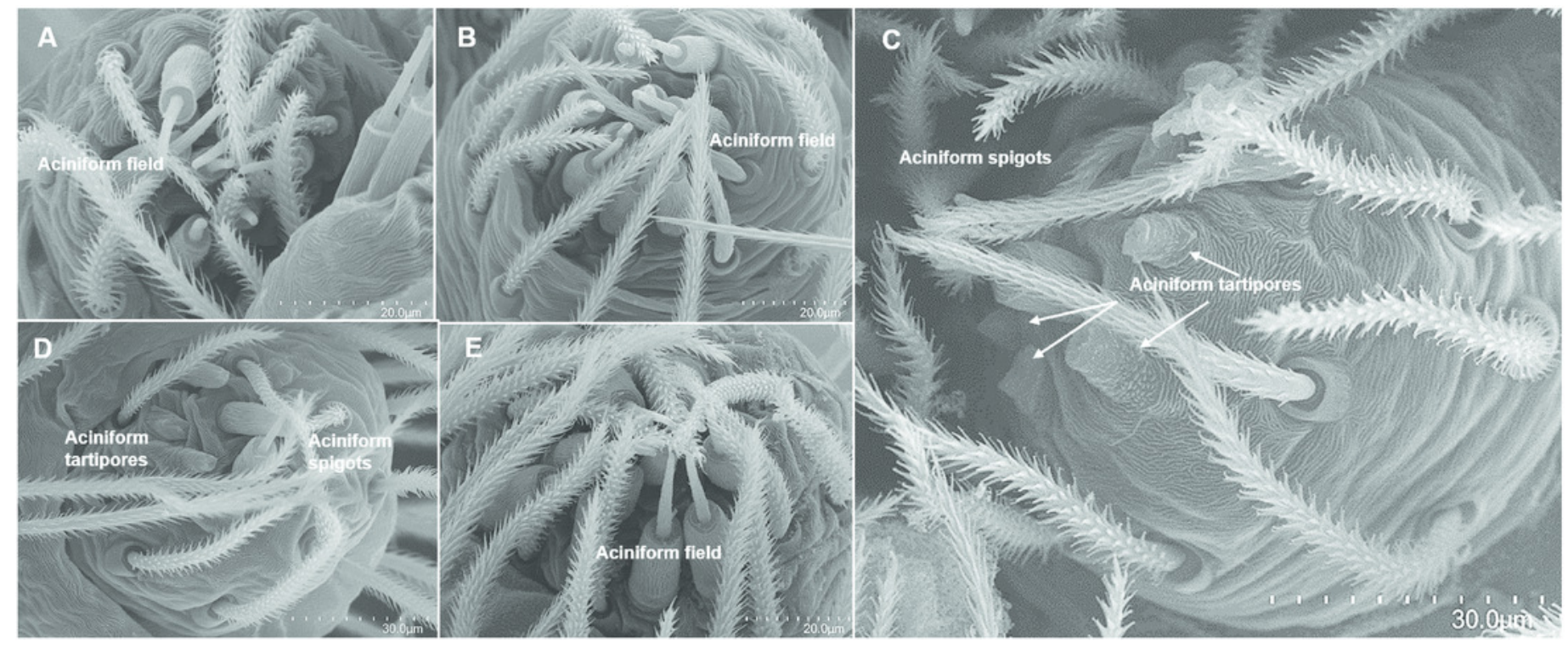




\section{Figure 9}

\section{ACE results for foraging strategy.}

Phylogram with ancestral character estimation of foraging strategy (Strategy), web or no web (loss) on the ultrametric tree with five additional taxa. Clearly, the ancestral state was web spinning (red).

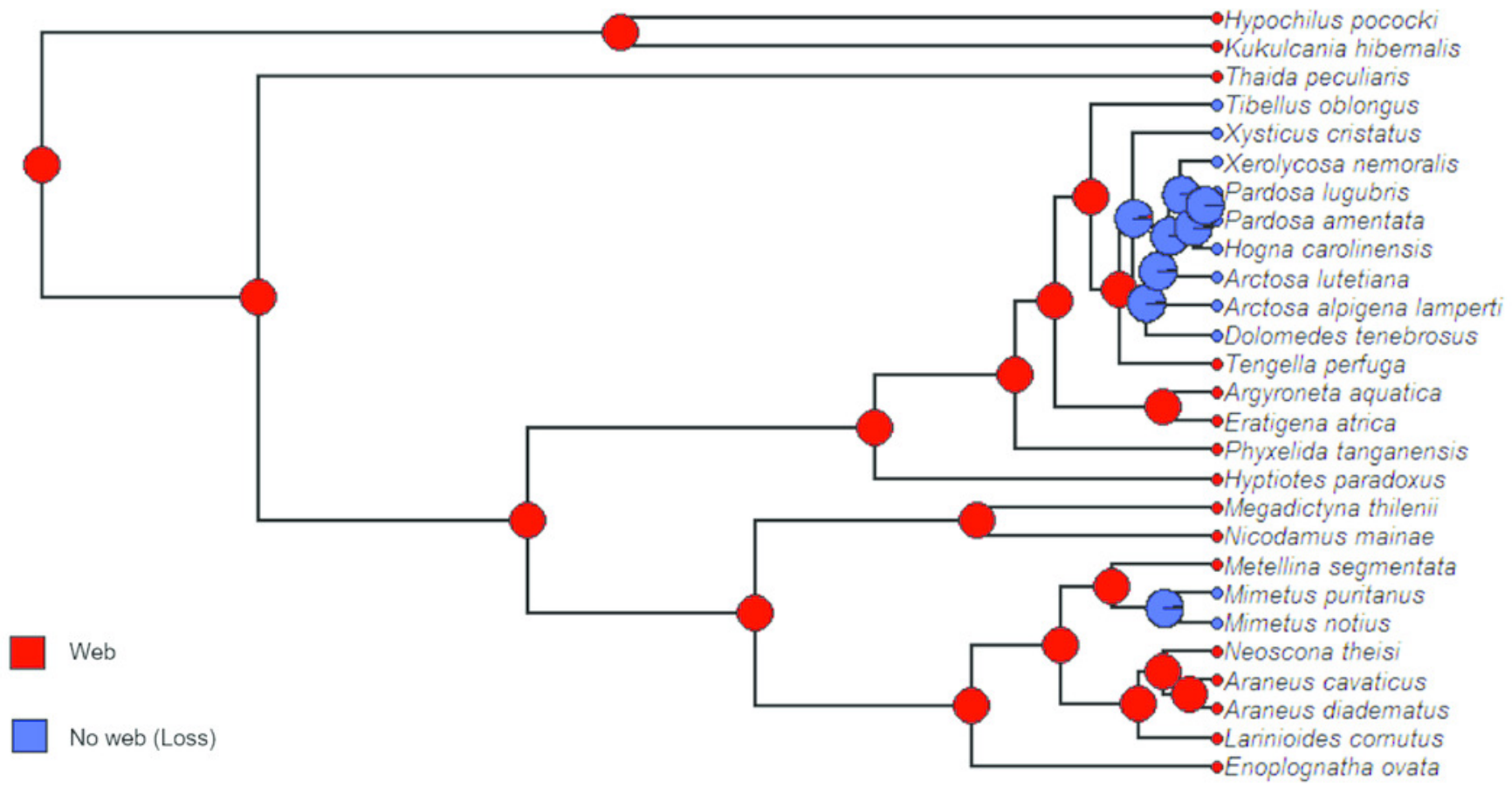




\section{Figure 10}

\section{ACE results for specific foraging strategies.}

Phylogram with ancestral character estimation of specific foraging strategies on the ultrametric tree with five additional taxa. Specific strategies include: sit \& wait, ambush, sit \& pursue, stalking, active, sheet web, funnel web, orb web and tangle web.

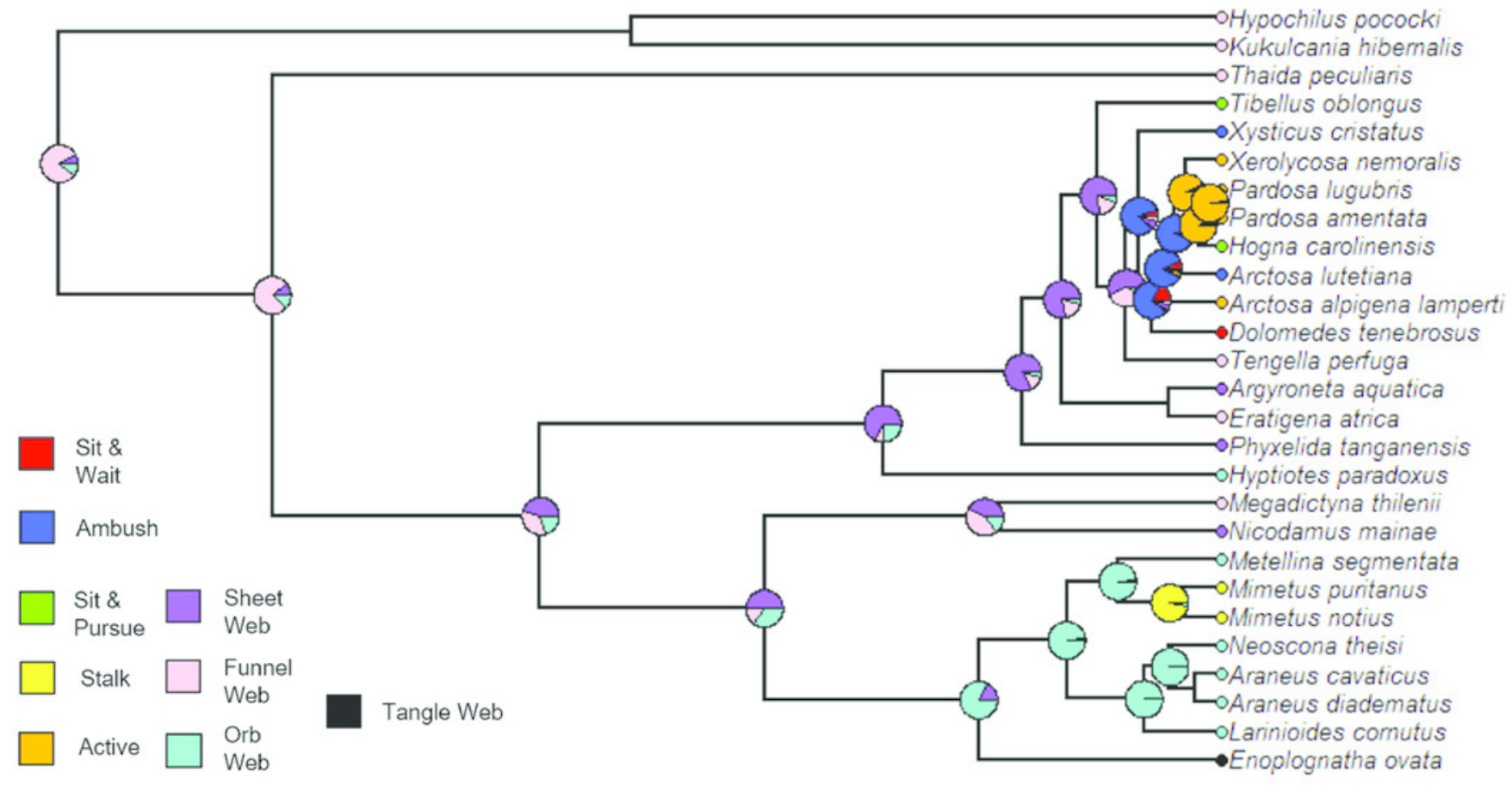




\section{Figure 11}

ACE results for main type of silk utilized by a species.

Phylogram with ancestral character estimation of Silk (main type of silk expressed) on the ultrametric tree with five additional taxa. Silk types include: none, burrow, aciniform, cribellate and viscous. This analysis suggests that the ancestral state for these clades is cribellate (yellow).

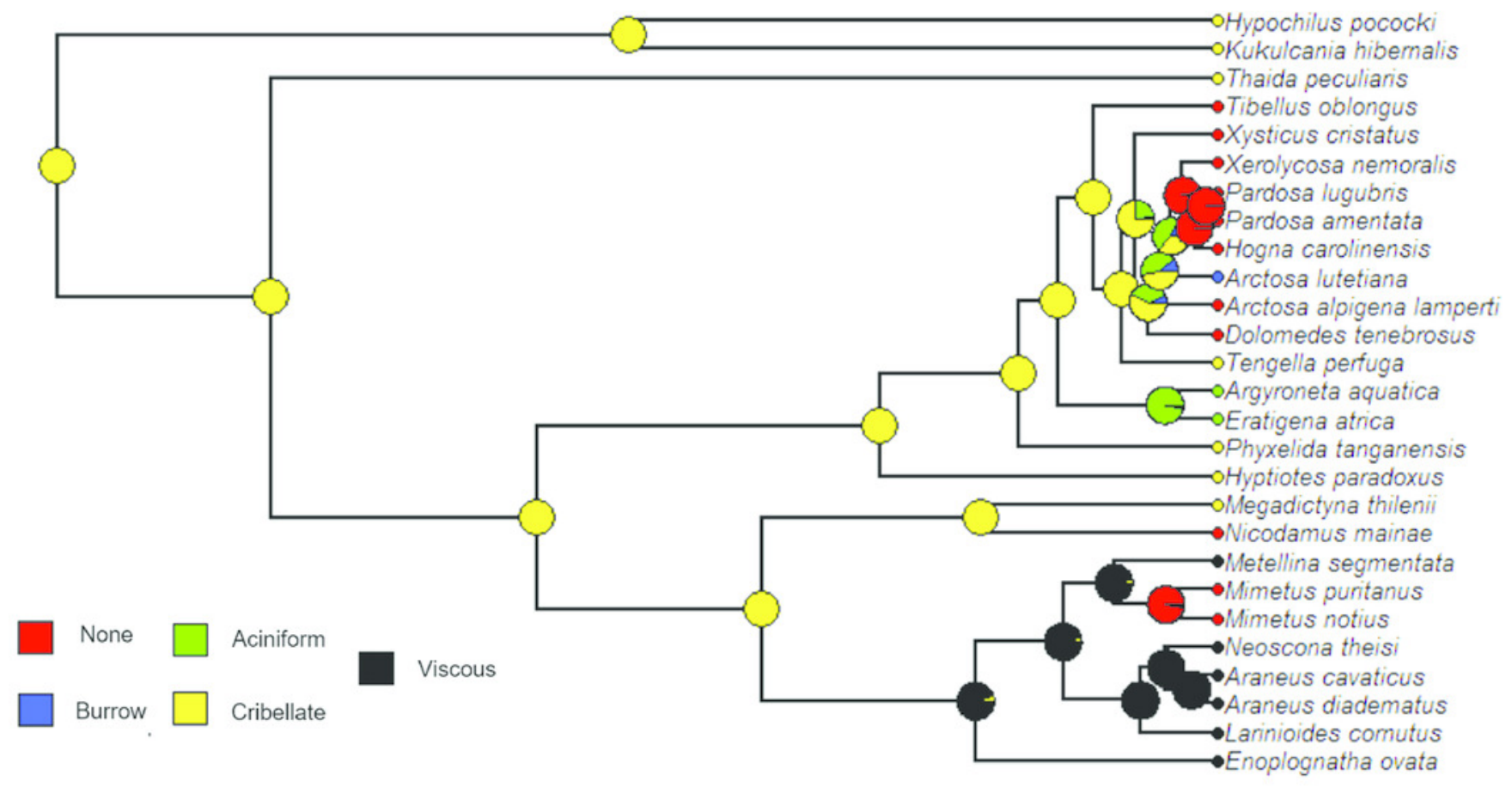




\section{Figure 12}

ACE results for variety of spigots possessed by a species.

Phylogram with ancestral character estimation of Type of spigots (variety of spigot types possessed) on the ultrametric tree with five additional taxa. These included several states, including the standard 7 spigots, along with additional spigots increasing in diversity. Std $7=$ standard 7; MsPi = modified piriform gland spigots; $\mathrm{MS}=$ modified spigot; Crib = cribellum;

Para = paracribellar spigots; $\mathrm{Ag}=$ aggregate gland spigots; $\mathrm{FI}=$ flagelliform gland spigot;

Pseudo $=$ pseudoflagelliform gland spigot.

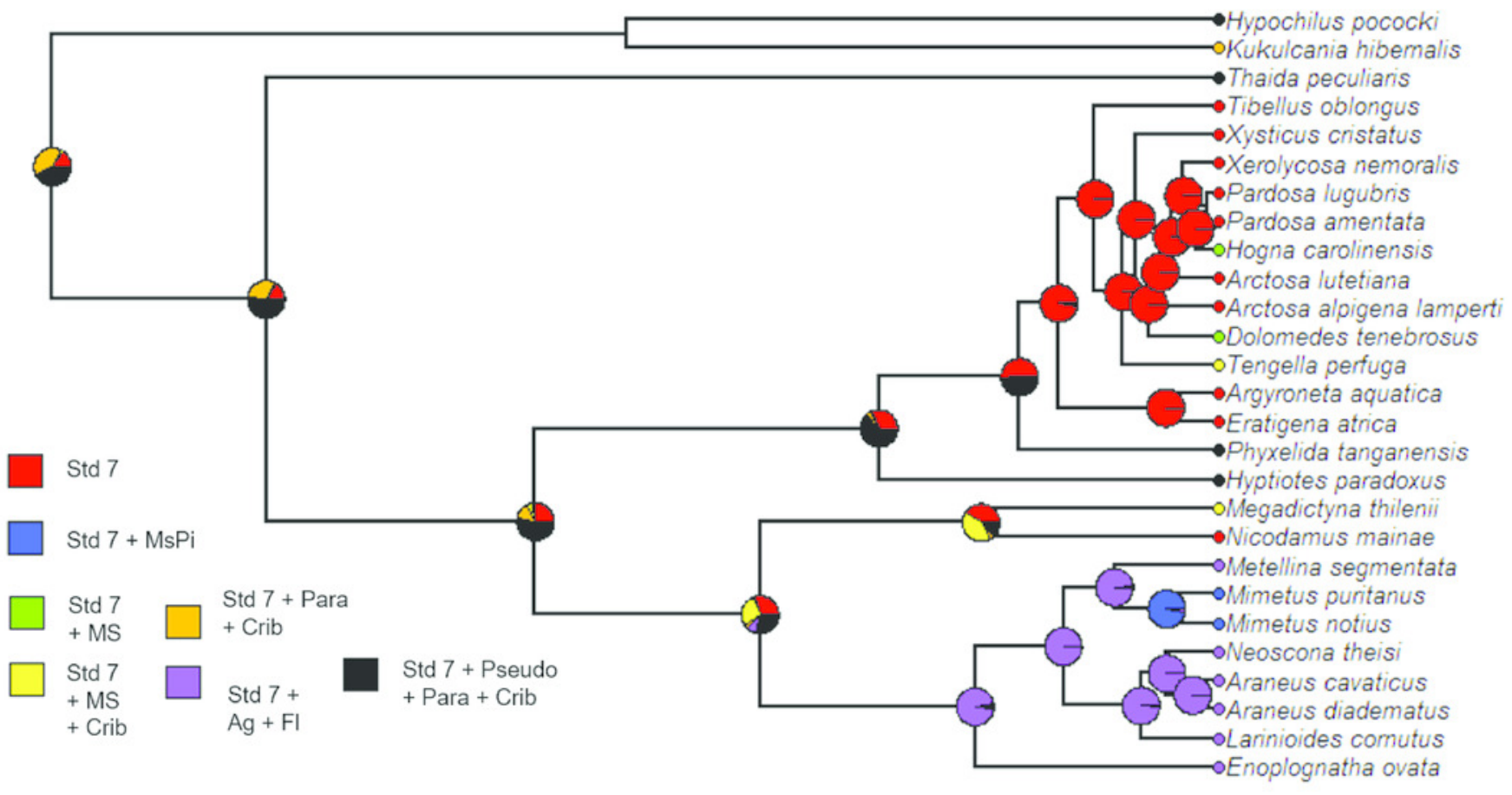

